\title{
Efficacy and Safety of Lopinavir/Ritonavir for Treatment of COVID-19: A
}

\section{Systematic Review and Meta-Analysis}

\section{Mansour Tobaiqy, ${ }^{1}$ Saad Alhumaid, ${ }^{2}$ Abbas Al Mutair ${ }^{3}$}

1- Department of Pharmacology, College of Medicine, University of Jeddah, Jeddah, Saudi Arabia

2- Drug Information and Research Department, Administration of Pharmaceutical Care, Ministry of Health, Al-Ahsa, Saudi Arabia

3- Research Center, Dr Sulaiman Al Habib Medical Group, Riyadh, Saudi Arabia

\section{Authors' Contributions}

Mansour Tobaiqy conceived the study and, together with Saad Alhumaid and Abbas Al Mutair designed and performed the study. The statistical analysis was performed by Saad Alhumaid and the manuscript was written by all of the authors.

\author{
Corresponding Author \\ Dr. Mansour Tobaiqy \\ BSc, MSc, Clin Pharmacol, PhD, PgCert \\ Assistant Professor \\ Department of Pharmacology \\ College of Medicine \\ University of Jeddah \\ P. O. Box 45311 Jeddah 21512 \\ E-mail: mtobaiqy@uj.edu.sa
}


medRxiv preprint doi: https://doi.org/10.1101/2020.06.16.20133298; this version posted June 19, 2020. The copyright holder for this preprint (which was not certified by peer review) is the author/funder, who has granted medRxiv a license to display the preprint in perpetuity. It is made available under a CC-BY-NC-ND 4.0 International license .

\begin{abstract}
Background

Since the emergence of COVID-19, the world has been desperate to find effective therapeutics and vaccinations to treat hundreds of thousands of affected patients and to suppress the spread of this global pandemic. Lopinavir-ritonavir (LPV/RTV) is an HIV antiviral combination that has been considered for treatment of this disease.
\end{abstract}

\title{
Aim of the study
}

This systematic review and meta-analysis aimed to assess the efficacy and safety of lopinavir/ritonavir in COVID-19 patients in the extant published research. A systematic review protocol was developed based on PRISMA-P and the PRISMA statement. Published English and non-English articles written since December 1, 2019 were selected for review from 8 electronic databases.

Readily accessible full articles (cohort studies and clinical trials) which specifically mentioned lopinavir/ritonavir and patients with lab-confirmed SARS-CoV-2 or COVOID-19 of any age were included. Three researchers separately evaluated the bias in the reported articles. We conducted a systematic review and meta-analysis with the objective of evaluation of the safety and efficacy of LPV/RTV alone or in combination with other drugs with regard to time to becoming PCR negative, time to body temperature normalization and cough relief, radiological progression, and safety. Review Manager (RevMan) was used to conduct all statistical analyses and generate the forest plots. Meta-analyses were performed using the Mantel Hazel method or the inverse variance method for dichotomous data and continuous data respectively.

\section{Results}

Non-duplicate articles $(n=76)$ were evaluated for possible inclusion. A consensus was reached to select 29 articles for full-text screening, only 11 articles comprised 1,192 patients were included in this study, and six of which were included for meta-analysis.

In terms of virological cure (PCR negative), three studies reported less time in days to achieve a virological cure for LPV/RTV arm relative to no antiviral therapy (conventional) (mean difference $=-0.81$ day; 95\% CI, -4.44 to $2.81 ; P=0.007, I^{2}=$ $80 \%)$. However, the overall effect was not significant $(P=0.66)$. When comparing LPV/RTV arm to umifenovir arm, a favorable affect was observed for umifenovir arm, but not statically significant (mean difference $=0.95$ day; $95 \% \mathrm{CI},-1.11$ to $3.01 ; P=$ $0.09, I^{2}=58 \%$ ).

In terms of time to body normalization and cough relief (clinical cure), two studies reported on time to temperature normalization with no significant effect of LPV/RTV (n $=93)$ versus umifenovir $(\mathrm{n}=71)$ arm $),(\mathrm{OR}=0.87$ day; $95 \% \mathrm{CI}, 0.42$ to $1.78 ;(P=$ $\left.0.70), \mathrm{I}_{2}=0 \%\right)$, or alleviation of cough duration $(\mathrm{p}=0.69)$.

In terms of CT evidence of radiological progression of pneumonia/lung damage, treatment with lopinavir/ritonavir resulted in no significant decrease in the radiological progression $\left(\mathrm{OR}=0.80 ; 95 \% \mathrm{CI}, 0.42\right.$ to $\left.1.54 ; P=0.59, I^{2}=81 \%\right)$, In terms of safety, a greater number of adverse events were reported for lopinavir/ritonavir $(n=45)$ relative to 
medRxiv preprint doi: https://doi.org/10.1101/2020.06.16.20133298; this version posted June 19, 2020. The copyright holder for this preprint (which was not certified by peer review) is the author/funder, who has granted medRxiv a license to display the preprint in perpetuity.

It is made available under a CC-BY-NC-ND 4.0 International license.

the umifenovir $\operatorname{arm}(\mathrm{n}=14)$ and conventional treatments $(\mathrm{n}=10), P=0.004,0,0007$, respectively

\section{Conclusions}

The small number of studies included in this systematic review and meta-analysis study did not reveal any statistically significant advantage in efficacy of lopinavir-ritonavir in COVID-19 patients, over conventional or other antiviral treatments. This result might not reflect the actual evidence.

Keywords: 2019-nCoV, COVID-19, efficacy, kaletra, lopinavir/ritonavir, meta-analysis, novel coronavirus, safety, SARS-CoV-2, systematic review, treatment 


\section{Introduction}

Since the emergence of an unknown viral infection in China in December 2019 and following the identification of this infection as 2019-new coronavirus disease (2019-nCoV, also known as COVID-19), caused by severe acute respiratory syndrome coronavirus 2 (SARS-CoV-2) [1], the world is desperate to find effective therapeutics and vaccinations to treat hundred thousand of affected patients and to reduce the spread of this global pandemic [2].

As June 2, there are 1104 registered clinical trials of COVID-19 therapeutics or vaccinations worldwide that either ongoing or recruiting patients; however, no drug or vaccine has officially been approved for COVID-19 [2, 3]. These trials have produced mixed and conflicting results of positive or negative outcomes and inclusive evidence of efficacy or safety, that render the suspension of some trials inevitable, as in the hydroxychloroquine trials, which was suggested by World Health Organization (WHO) in light of safety concerns [4]. This decision was reversed on June 3, 2020 [5] following a retraction of the research article by Lancet as certain authors were not granted access to the underlying data [6].

Lopinavir-ritonavir is a protease inhibitor and nucleoside analogue combination used for human immunodeficiency virus (HIV-1), and is also considered a potential treatment for COVID-19 [7], as its therapeutic value in the treatment of COVID-19 emerged from invitro studies that demonstrated inhibition of several viral corona respiratory illnesses, 
medRxiv preprint doi: https://doi.org/10.1101/2020.06.16.20133298; this version posted June 19, 2020. The copyright holder for this preprint (which was not certified by peer review) is the author/funder, who has granted medRxiv a license to display the preprint in perpetuity.

It is made available under a CC-BY-NC-ND 4.0 International license .

including severe acute respiratory syndrome (SARS-CoV), and Middle East Respiratory Syndrome (MERS) [8. 9, 10].

Lopinavir (LPV) is an aspartic acid protease inhibitor of HIV, where inhibition of proteases enzymes is essential for the intervening of the viral infectious cycle, and is co-formulated with ritonavir to boost the pharmacokinetic activity and half-life of lopinavir through inhibition of Cytochromes P450, providing adequate suppression of viral load and constant improvements in CD4+ cell counts, as demonstrated in randomized trials in naïve and experienced adults and children HIV patients [7].

Lopinavir/ritonavir is available as a single-tablet formulation (Kaletra ${ }^{\circledR}$ ) in dosage strengths of $400 / 100 \mathrm{mg}$ or $200 / 100 \mathrm{mg}$, and in clinical trials, this combination reduced rates of acute respiratory distress syndrome (ARDS) or death compared to supportive care or ribavirin alone in a matched cohort group during the early phase of viral acquisition [8].

Lopinavir-ritonavir is being examined in several international clinical trials, including the RECOVERY trial and SOLIDARITY WHO trial [11], but did not gain authorization to be used emergently in the current pandemic in the USA by the Food and Drug Administration (FDA), which has approved only three pharmacologically different therapeutics for treatments of COVID-19, including antibiotic-hydroxychloroquine, immunotherapyconvalescent plasma therapy, and antiviral-remdesivir $[2,11]$.

Among the clinical trials that did not find positive results for lopinavir-ritonavir, a study conducted by Bin Cao et al. and published in New England Journal of Medicine [12] revealed that treatment with lopinavir-ritonavir was not associated with clinical 
medRxiv preprint doi: https://doi.org/10.1101/2020.06.16.20133298; this version posted June 19, 2020. The copyright holder for this preprint (which was not certified by peer review) is the author/funder, who has granted medRxiv a license to display the preprint in perpetuity.

It is made available under a CC-BY-NC-ND 4.0 International license .

improvement beyond standard care or reduction in mortality rate at 28 days in hospitalized adult patients with severe COVID-19 [12].

To date, lopinavir/ritonavir combination is available in most countries' therapeutics guidelines including USA [13], Saudi Arabia [14], and Ireland [15], which means that the medicine has tenable evidence of efficacy; however, considering early negative and conflicting results have emerged [12], there is a need to assess the efficacy and safety of this COVID-19 treatment in a systematic manner.

\section{Aim of the study}

This systematic review and meta-analysis aim to assess the efficacy and safety of lopinavir/ritonavir in COVID-19 patients in published research.

\section{Methods}

This systematic review was conducted with reference to the basics of Cochrane Handbook for Systematic Reviews of Interventions (16), described as stated by the Preferred Reporting Items for Systematic reviews and Meta-Analysis (PRISMA) statement [17, 18].

\section{Search strategy and selection criteria}

A systematic review protocol was developed based on PRISMA-P and the PRISMA statement. Published articles from December 1, 2019 to May 22, 2020 were selected for review from 8 electronic databases (PubMed, CINAHL, Embase, medRxiv, Proquest, Wiley online library, Medline, and Nature). 
The focus of the review was lopinavir/ritonavir treatment in COVID-19 patients. The primary outcome was the efficacy of lopinavir/ritonavir in COVID-19 patients. The secondary outcome was adverse events associated with its use.

\section{Inclusion criteria}

Readily accessible peer-reviewed full articles, observational cohort studies, and clinical trials were included.

Participants: Patients with lab-confirmed COVOID-19 of any age were included.

\section{Intervention}

The interventions were lopinavir/ritonavir versus a control of either no antiviral therapy (conventional therapy), standard therapy, or lopinavir/ritonavir with other antiviral agents.

\section{Objectives}

A. Virological cure on day 7 after initiation of therapy (+ve to -ve PCR: non-detection of SARS-CoV-2 in nasopharyngeal swab).

B. Clinical cure (time to body temperature normalization and time to cough relief).

C. Radiological progression during drug treatment.

D. Safety and tolerability of lopinavir/ritonavir.

\section{Comparisons}

A. lopinavir/ritonavir vs no antiviral therapy (conventional therapy)/control.

B. lopinavir/ritonavir in combination of other agents versus conventional therapy/control. 


\section{Searching keywords}

The search keywords included 2019-nCoV, 2019 novel coronavirus, COVID-19, coronavirus disease 2019, SARS-COV-2, lopinavir, ritonavir, combination, kaletra, treatment, efficacy, clinical trial, cohort, retrospective, and prospective.

\section{Exclusion criteria}

Types of articles that were excluded included duplicate articles, editorials, reviews, case reports, and letters to editors.

Any research articles that did not include data on lopinavir/ritonavir use, did not include control patients' group, or reported combined use of lopinavir/ritonavir with other antiviral medications were also excluded.

\section{Data extraction and analysis}

Two reviewers (MT and SA) independently screened the titles with abstracts using the selection criteria. For relevant articles, full texts were obtained for further evaluation. Disagreements between the two reviewers after full text screening were reconciled via consensus by a third reviewer (AA) [19].

Inclusions and exclusions were recorded following PRISMA guidelines presented in the form of a PRISMA flow diagram and detailed reasons recorded for exclusion. Articles were categorized as clinical trials or cohort studies. The following data were extracted from selected studies: authors; publication year; study location; study design and setting; sample size, age, and gender; details of study intervention and control therapies in addition to data 
medRxiv preprint doi: https://doi.org/10.1101/2020.06.16.20133298; this version posted June 19, 2020. The copyright holder for this preprint (which was not certified by peer review) is the author/funder, who has granted medRxiv a license to display the preprint in perpetuity.

It is made available under a CC-BY-NC-ND 4.0 International license.

on adverse events and treatment outcomes; assessment of study risk of bias; and remarks on noticeable findings.

\section{Risk of biased evaluation of included studies}

The quality assessment of the studies was undertaken based on the revised Cochrane risk of bias tool (RoB 2.0) for randomized controlled studies [20]. ROBINS-I tool was used to asses non-randomized interventional studies [21], and Newcastle Ottawa Scale for observational cohort studies [22]. Critical appraisal checklists appropriate to each study design were applied and checked by the third-team member.

Three investigators (MT, SA, and AA) separately evaluated the possibility of bias using these tools. Publication bias was not evaluated by funnel plot as there was only three studies which were included in the meta-analysis part of the study.

\section{Assessment of heterogeneity}

Statistical heterogeneity was evaluated using the $\chi^{2}$ test and $I^{2}$ statistics $(17,18)$. An $I^{2}$ value of 0 to $<40 \%$ was not considered as significant, $30 \%$ to $60 \%$ was regarded as moderate heterogeneity, $50 \%$ to $90 \%$ was considered substantial heterogeneity, and $75 \%$ to $100 \%$ was considered significant heterogeneity.

\section{Statistical analysis}

Because all of the data were continuous and dichotomous data, we used either odds ratio (OR) or mean difference for estimating the point estimate, along with a $95 \%$ confidence interval (CI). In the absence of significant clinical heterogeneity, we performed the metaanalysis using the Mantel Hazel method or inverse variance method for dichotomous 
medRxiv preprint doi: https://doi.org/10.1101/2020.06.16.20133298; this version posted June 19, 2020. The copyright holder for this preprint

(which was not certified by peer review) is the author/funder, who has granted medRxiv a license to display the preprint in perpetuity.

It is made available under a CC-BY-NC-ND 4.0 International license.

data and continuous data respectively. Employing a conservative approach, a random effects model was used, which produces wider CIs than a fixed effect model [16].

Review Manager (Version 5.3, Oxford, UK; The Cochrane Collaboration, 2014) was used to conduct all statistical analyses and generate the forest plots [18].

\section{Results}

A total of 8 literature databases were screened and 76 non-duplicate articles was identified, which were evaluated for possible inclusion using titles and abstracts. Out of these, 29 articles were selected for full-text screening and finally, eleven articles (total participants $=1,192$ ) were included in the systematic review and six articles were included in the meta-analysis. 18 articles were excluded following full-text screening (reasons: review $=5$, study with no relative data $=6, \mathrm{LPV} / \mathrm{RTV}$ use data not available $=2$, no control patients in the study $=1$, combined LPV/RTV use with other antiviral therapies/other medications data $=2$, no extractable data $=2$ ). The PRISMA chart for the included studies is displayed in Figure 1. The details of the included studies are depicted in Table 1. Among these, two articles were in preprint versions [23, 24]. 
medRxiv preprint doi: https://doi.org/10.1101/2020.06.16.20133298; this version posted June 19, 2020. The copyright holder for this preprint (which was not certified by peer review) is the author/funder, who has granted medRxiv a license to display the preprint in perpetuity.

\section{It is made available under a CC-BY-NC-ND 4.0 International license .}

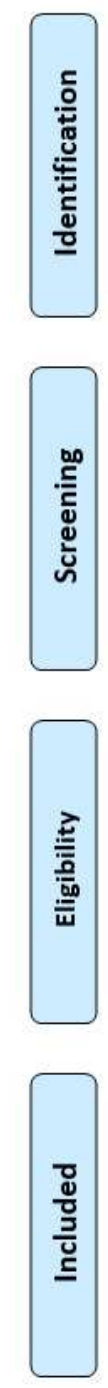

\section{Records identified through database searching} $(n=76)$
Additional records identified through other sources $(n=7)$

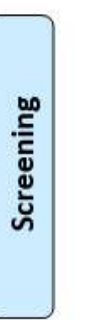

Records after duplicates removed

$$
(n=67)
$$
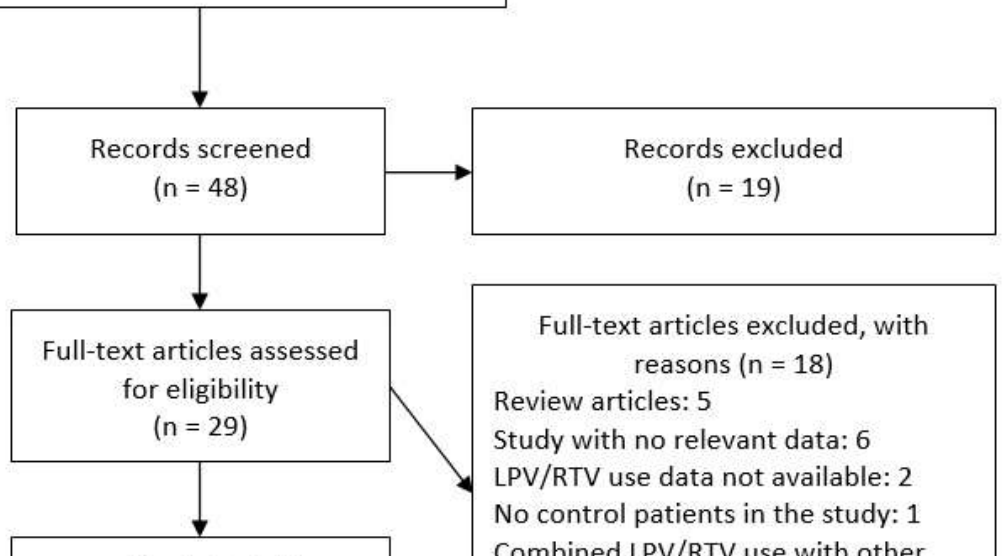

Studies included in qualitative synthesis $(n=11)$

Full-text articles excluded, with reasons $(n=18)$

Review articles: 5

Study with no relevant data: 6

LPV/RTV use data not available: 2

No control patients in the study: 1 Combined LPV/RTV use with other antiviral therapies/other medications data: 2

No extractable data: 2

Studies included in quantitative synthesis (meta-analysis) $(n=6)$

Figure 1: PRISMA flow chart of the included studies. LPV/RTV, lopinavir/ritonavir; PRISMA, Preferred Reporting Items for Systematic reviews and Meta-analysis. 
Table 1: Data extracted from included papers $(n=11)$

\begin{tabular}{|c|c|c|c|c|c|c|c|c|c|c|}
\hline $\begin{array}{c}\text { Author, } \\
\text { year } \\
\text { [reference] } \\
\text {, study } \\
\text { location }\end{array}$ & $\begin{array}{l}\text { Study design } \\
\text { and setting }\end{array}$ & $\begin{array}{l}\text { Age } \\
\text { (year) }\end{array}$ & $\begin{array}{l}\text { Male, } \\
\mathrm{n}(\%)\end{array}$ & Population & Intervention & Control & Outcome & $\begin{array}{l}\text { AEs in LPV/RTV } \\
\text { and control arm }\end{array}$ & $\begin{array}{c}\text { Assessment } \\
\text { of study risk } \\
\text { of bias (tool } \\
\text { used; } \\
\text { finding) }\end{array}$ & Remark \\
\hline $\begin{array}{l}\text { Cai et al. } \\
2020[] ; \\
\text { China }\end{array}$ & $\begin{array}{l}\text { Nonrandomized } \\
\text { open-label } \\
\text { controlled trial; } \\
\text { single center }\end{array}$ & $\begin{array}{c}\text { Median } \\
\text { (IQR), } \\
47(35.7- \\
\quad 61)\end{array}$ & $\begin{array}{c}35 \\
(43.8)\end{array}$ & $\begin{array}{c}\text { Confirmed COVID- } \\
19 \text { cases aged 16- } \\
75 \mathrm{y} \\
\text { No significant } \\
\text { differences between } \\
\text { the baseline } \\
\text { characteristics of } \\
\text { the two arms } \\
\text { FPV treated } \\
\text { patients were older } \\
\text { (43 y) compared } \\
\text { with LPV/RTV arm } \\
\text { (49 y) } \\
\text { All patients were } \\
\text { moderate cases as } \\
\text { defined by NHC [1] }\end{array}$ & $\begin{array}{l}45 \text { patients } \\
\text { received: } \\
\text { LPV/RTV } \\
\text { (oral): } 400 \\
\text { mg/100 mg } \\
\text { twice daily } \\
\text { on days } 1- \\
14 \\
\text { PLUS } \\
\text { IFN- } \alpha 1 b \\
\text { (aerosol } \\
\text { inhalation): } \\
5 \text { million } \\
\text { IUs twice } \\
\text { daily }\end{array}$ & 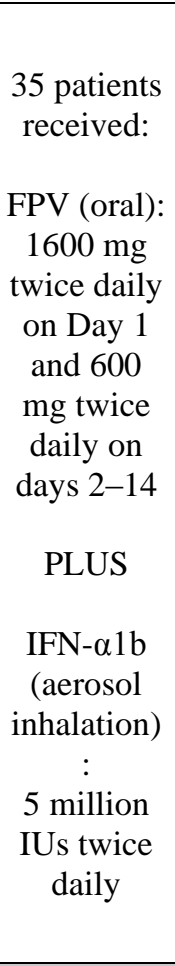 & $\begin{array}{c}\text { Viral clearance: shorter viral } \\
\text { clearance time for FPV arm } \\
\text { (median (interquartile range, } \\
\text { IQR), } 4(2.5-9) \mathrm{d} \text { versus } 11 \text { ( } 8- \\
13) \mathrm{d}, \mathrm{p}<0.001) \\
\text { Chest CT changes: more imaging } \\
\text { improvement rate in FPV arm } \\
(91.43 \% \text { vs } 62.22 \%), \mathrm{p}=0.004\end{array}$ & $\begin{array}{l}\text { FPV arm patients } \\
\text { had less AEs } \\
\text { compared to the } \\
\text { LPV/RTV group } \\
(11.43 \% \text { vs } \\
55.56 \%)(\mathrm{p}<0.001) \\
\\
\text { Two patients had } \\
\text { diarrhea, one had a } \\
\text { liver injury, and one } \\
\text { had a poor diet in } \\
\text { the FPV arm } \\
\\
\text { There were five } \\
\text { patients with } \\
\text { diarrhea, five with } \\
\text { vomiting, six with } \\
\text { nausea, four with } \\
\text { rash, three with } \\
\text { liver injury, and } \\
\text { two with chest } \\
\text { tightness and } \\
\text { palpitations in the } \\
\text { LPV/RTV arm }\end{array}$ & $\begin{array}{l}\text { ROBINS-I, } \\
\text { moderate } \\
\text { risk of bias }\end{array}$ & $\begin{array}{c}\text { Two patient } \\
\text { in the FPV } \\
\text { group turned } \\
\text { negative } \\
\text { for viral } \\
\text { RNA } \\
\text { detection in } \\
\text { nasopharyng } \\
\text { eal swabs at } \\
\text { days } 18 \text { and } \\
21 \\
\text { For patients } \\
\text { in the } \\
\text { LPV/RTV } \\
\text { group, the } \\
\text { viral RNA } \\
\text { detection all } \\
\text { turned } \\
\text { negative } \\
\text { within } 27 \mathrm{~d}\end{array}$ \\
\hline $\begin{array}{l}\text { Cao et al. } \\
2020[] ; \\
\text { China }\end{array}$ & $\begin{array}{c}\text { Randomized } \\
\text { open-label } \\
\text { controlled trial; }\end{array}$ & $\begin{array}{l}\text { Median } \\
\text { (IQR), }\end{array}$ & $\begin{array}{c}120 \\
(60.3)\end{array}$ & $\begin{array}{l}\text { Confirmed Covid- } \\
19, \text { having an } \mathrm{SaO}_{2} \\
\text { of } 94 \% \text { or less or a }\end{array}$ & $\begin{array}{l}99 \text { patients } \\
\text { received: }\end{array}$ & $\begin{array}{c}100 \\
\text { patients } \\
\text { received: }\end{array}$ & $\begin{array}{l}\text { Time to clinical improvement: no } \\
\text { difference in the time to clinical } \\
\text { improvement for patients in the }\end{array}$ & $\begin{array}{l}\text { GI AEs were more } \\
\text { common in the } \\
\text { LPV/RTV group, }\end{array}$ & $\begin{array}{l}\text { RoB 2, low } \\
\text { risk of bias }\end{array}$ & $\begin{array}{l}\text { Most } \\
\text { patients } \\
\text { were }\end{array}$ \\
\hline
\end{tabular}




\begin{tabular}{|c|c|c|c|c|c|c|c|c|c|c|}
\hline & single center & $\begin{array}{c}58(49- \\
68)\end{array}$ & & $\begin{array}{l}\text { ratio of the } \mathrm{PaO}_{2} \text { to } \\
\text { the } \mathrm{FiO}_{2} \text { of less } \\
\text { than } 300 \mathrm{mmHg} \\
\\
\text { No important } \\
\text { between-group } \\
\text { differences in } \\
\text { demographic } \\
\text { characteristics, } \\
\text { baseline laboratory } \\
\text { test results, } \\
\text { distribution of } \\
\text { ordinal scale scores, } \\
\text { or NEWS2 scores } \\
\text { at enrollment }\end{array}$ & $\begin{array}{l}\text { LPV/RTV } \\
\text { (oral): } \\
400 / 100 \mathrm{mg} \\
\text { twice daily } \\
\text { PLUS } \\
\text { standard } \\
\text { care* for } 14 \\
\text { days }\end{array}$ & $\begin{array}{l}\text { Standard } \\
\text { care* alone } \\
\text { for } 14 \text { days }\end{array}$ & $\begin{array}{l}\text { LPV/RTV group and the } \\
\text { standard-care* group (hazard ratio } \\
\text { for clinical improvement, } 1.31 \text {; } \\
95 \% \text { confidence interval [CI], } \\
0.95 \text { to } 1.80 \text { ) } \\
\text { Mortality at } 28 \text { days was similar } \\
\text { in the two groups ( } 19.2 \% \text { vs. } \\
25.0 \% \text {; difference, }-5.8 \\
\text { percentage points; } 95 \% \text { CI, }-17.3 \\
\text { to } 5.7 \text { ) } \\
\text { Percentages of patients with } \\
\text { detectable viral RNA at various } \\
\text { time points were similar } \\
\text { In a modified ITT analysis, } \\
\text { LPV/RTV led to a median time to } \\
\text { clinical improvement that was } \\
\text { shorter by } 1 \text { day than that } \\
\text { observed with standard care* } \\
\text { (hazard ratio, 1.39; } 95 \% \text { CI, } 1.00 \\
\text { to } 1.91 \text { ) }\end{array}$ & $\begin{array}{l}\text { but serious AEs } \\
\text { were more common } \\
\text { in the standard } \\
\text { care* group. } \\
\text { LPV/RTV } \\
\text { treatment was } \\
\text { stopped early in } \\
13.8 \% \text { because of } \\
\text { AEs }\end{array}$ & & $\begin{array}{c}\text { severely } \\
\text { unwell and } \\
\text { required } \\
\text { urgent } \\
\text { clinical } \\
\text { attention } \\
\text { Systemic } \\
\text { glucocorticoi } \\
\text { ds were } \\
\text { administered } \\
\text { (33.0\% in } \\
\text { patients of } \\
\text { LPV/RTV } \\
\text { group and } \\
35.7 \% \text { in } \\
\text { patients of } \\
\text { standard- } \\
\text { care* alone } \\
\text { group) }\end{array}$ \\
\hline $\begin{array}{l}\text { Hung et al. } \\
2020 \text { []; } \\
\text { Hong } \\
\text { Kong }\end{array}$ & $\begin{array}{l}\text { Randomized } \\
\text { open-label trial; } \\
\text { multicenter }\end{array}$ & $\begin{array}{c}\text { Median } \\
\text { (IQR), } \\
52(32- \\
62)\end{array}$ & $\begin{array}{c}68 \\
(54)\end{array}$ & $\begin{array}{l}\text { Confirmed COVID- } \\
19 \\
\text { cases and aged at } \\
\text { least } 18 \text { years, an } \\
\text { NEWS2 of at least } \\
1 \text {, and symptom } \\
\text { duration of } 14 \text { days } \\
\text { or less upon } \\
\text { recruitment } \\
\\
\text { Age, sex, and } \\
\text { baseline } \\
\text { demographics in }\end{array}$ & $\begin{array}{l}41 \text { patients } \\
\text { received: } \\
\text { LPV/RTV } \\
\text { (oral): } \\
400 / 100 \mathrm{mg} \\
\text { twice daily } \\
\text { (control } \\
\text { group) for } \\
14 \text { days }\end{array}$ & $\begin{array}{l}86 \text { patients } \\
\text { received: } \\
\text { LPV/RTV } \\
\text { (oral): } \\
400 / 100 \\
\text { mg twice } \\
\text { daily } \\
\text { PLUS } \\
\text { Ribavirin } \\
\text { (oral): } 400 \\
\text { twice daily }\end{array}$ & $\begin{array}{l}\text { Combination group had a } \\
\text { significantly shorter median time } \\
\text { from start of study treatment to } \\
\text { negative nasopharyngeal swab ( } 7 \\
\text { days [IQR 5-11]) than the } \\
\text { LPV/RTV group (12 days [8-15]; } \\
\text { hazard ratio } 4 \cdot 37 \text { [95\% CI 1.86- } \\
10 \cdot 24], \mathrm{p}=0 \cdot 0010)\end{array}$ & $\begin{array}{l}\text { AEs included } \\
\text { nausea and } \\
\text { diarrhoea with no } \\
\text { difference between } \\
\text { the two groups. One } \\
\text { patient in the } \\
\text { control group } \\
\text { discontinued } \\
\text { LPV/RTV because } \\
\text { of biochemical } \\
\text { hepatitis }\end{array}$ & $\begin{array}{l}\text { RoB 2, some } \\
\text { concerns } \\
\text { risk of bias }\end{array}$ & $\begin{array}{l}\text { No patients } \\
\text { died during } \\
\text { the study }\end{array}$ \\
\hline
\end{tabular}




\begin{tabular}{|c|c|c|c|c|c|c|c|c|c|c|}
\hline & & & & $\begin{array}{l}\text { each group were } \\
\text { similar }\end{array}$ & & $\begin{array}{c}\text { PLUS } \\
\text { IFN-beta- } \\
\text { 1b (SCI): } \\
\text { three doses } \\
\text { of } 8 \\
\text { million IUs } \\
\text { of } \\
\text { interferon } \\
\text { beta-1b on } \\
\text { alternate } \\
\text { days } \\
\text { (combinati } \\
\text { on group); } \\
\text { for 14 days }\end{array}$ & & & & \\
\hline $\begin{array}{l}\text { Li et al. } \\
2020 \text { []; } \\
\text { China }\end{array}$ & $\begin{array}{l}\text { Randomized } \\
\text { blinded trial; } \\
\text { single center }\end{array}$ & $\begin{array}{c}\text { Mean } \\
\text { (SD), } \\
49.4 \\
(14.7)\end{array}$ & $\begin{array}{c}40 \\
(46.5)\end{array}$ & $\begin{array}{c}\text { Mild/moderate } \\
\text { confirmed COVID- } \\
19 \\
\text { cases aged 18-80 y } \\
\text { Baseline } \\
\text { characteristics of } \\
\text { the three groups } \\
\text { were comparable }\end{array}$ & $\begin{array}{l}34 \text { patients } \\
\text { received: } \\
\text { LPV/RTV } \\
\text { (oral): } \\
200 / 50 \mathrm{mg} \\
\text { twice daily } \\
\text { for } 7-14 \\
\text { days }\end{array}$ & $\begin{array}{c}35 \text { patients } \\
\text { received: } \\
\text { Umifenovi } \\
\text { r (oral): } \\
200 \mathrm{mg} \\
\text { three times } \\
\text { daily for } 7- \\
14 \text { days } \\
\text { OR } \\
17 \text { patients } \\
\text { received } \\
\text { no antiviral } \\
\text { therapy }\end{array}$ & $\begin{array}{l}\text { Rate of positive-to-negative } \\
\text { conversion of SARS-CoV-2 } \\
\text { nucleic acid was similar between } \\
\text { groups (all } p>0.05 \text { ) } \\
\text { There were no differences } \\
\text { between groups in the rates of } \\
\text { antipyresis, cough alleviation, or } \\
\text { improvement of chest CT at days } \\
7 \text { or } 14 \text { (all } p>0.05 \text { ) } \\
\text { At day } 7,23.5 \% \text { patients in the } \\
\text { LPV/RTV group, } 8.6 \% \text { in the } \\
\text { umifenovir group and } 11.8 \% \text { in } \\
\text { the control group showed a } \\
\text { deterioration in clinical status } \\
\text { from moderate to severe/critical } \\
\text { ( }=0.206 \text { ) }\end{array}$ & $\begin{array}{l}\text { Overall, 35.3\% } \\
\text { patients in the } \\
\text { LPV/RTV group } \\
\text { and } 14.3 \% \text { in the } \\
\text { umifenovir group } \\
\text { experienced AEs } \\
\text { No apparent AEs } \\
\text { occurred in the } \\
\text { control group }\end{array}$ & $\begin{array}{l}\text { RoB 2, high } \\
\text { risk of bias }\end{array}$ & $\begin{array}{l}\text { Study was } \\
\text { blinded to } \\
\text { participants, } \\
\text { physicians } \\
\text { and } \\
\text { radiologists } \\
\text { who } \\
\text { reviewed } \\
\text { data but } \\
\text { open label to } \\
\text { clinicians } \\
\text { who } \\
\text { recruited } \\
\text { patients and } \\
\text { research } \\
\text { staff } \\
\text { All three } \\
\text { groups were } \\
\text { treated with }\end{array}$ \\
\hline
\end{tabular}




\begin{tabular}{|c|c|c|c|c|c|c|c|c|c|c|}
\hline & & & & & & & & & & $\begin{array}{l}\text { Standard } \\
\text { care* if in } \\
\text { need }\end{array}$ \\
\hline $\begin{array}{l}\text { Lan et al. } \\
2020[] ; \\
\text { China }\end{array}$ & $\begin{array}{c}\text { Retrospective; } \\
\text { cohort; } \\
\text { multicenter }\end{array}$ & $\begin{array}{c}\text { Mean } \\
(\mathrm{SD}), \\
55.8 \\
(15.2)\end{array}$ & $\begin{array}{c}37 \\
(50.7)\end{array}$ & $\begin{array}{l}\text { Confirmed COVID- } \\
19 \\
\text { cases treated with } \\
\text { LPV/RTV alone or } \\
\text { combined with } \\
\text { umifenovir } \\
\text { Different age, sex, } \\
\text { and baseline } \\
\text { demographics in } \\
\text { each group }\end{array}$ & $\begin{array}{l}34 \text { patients } \\
\text { received: } \\
\\
\text { LPV/RTV } \\
\text { (oral): } \\
400 / 100 \mathrm{mg} \\
\text { twice daily } \\
\text { for } 14 \text { days }\end{array}$ & $\begin{array}{l}39 \text { patients } \\
\text { received: } \\
\text { LPV/RTV } \\
\text { (oral): } \\
400 / 100 \\
\text { mg twice } \\
\text { daily } \\
\text { PLUS } \\
\text { Umifenovi } \\
\text { r (oral): } \\
\text { 200mg } \\
\text { three times } \\
\text { daily; at } \\
\text { least for } 3 \\
\text { days }\end{array}$ & $\begin{array}{l}\text { Treatment with LPV/RTV alone } \\
\text { was not difference from } \\
\text { LPV/RTV combined with } \\
\text { umifenovir in overall cure rate } \\
\text { (92.3\% and } 97.1 \% \text {, respectively) } \\
\text { In a modified ITT analysis, } \\
\text { LPV/RTV combined with } \\
\text { umifenovir led to a median time } \\
\text { of hospital stay that was shorter } \\
\text { by } 1.5 \text { days (12.5 days vs. } 14 \\
\text { days) } \\
\text { COVID-19 RNA clearance was } \\
92.3 \% \text { in LPV/RTV and } 97.1 \% \text { in } \\
\text { combination therapies group } \\
\text { Mean time of virus turning } \\
\text { negative was } 11.5 \pm 9.0 \text { days in } \\
\text { combination group compared to } \\
9.9 \pm 7.5 \text { in single therapy group }\end{array}$ & Not reported & NOS, 5 & $\begin{array}{l}\text { All eligible } \\
\text { patients } \\
\text { received } \\
\text { standard } \\
\text { care* if } \\
\text { necessary }\end{array}$ \\
\hline $\begin{array}{l}\text { Wen et al. } \\
2020 \text { []; } \\
\text { China }\end{array}$ & $\begin{array}{c}\text { Retrospective; } \\
\text { cohort; } \\
\text { single center }\end{array}$ & $\begin{array}{c}\text { Mean } \\
\text { (SD), } \\
49.9 \\
(16.1)\end{array}$ & $\begin{array}{c}81 \\
(45.5)\end{array}$ & $\begin{array}{c}\text { Confirmed COVID- } \\
19 \\
\text { cases aged } \geq 18 \\
\text { years with hospital } \\
\text { stay longer than } 14 \\
\text { days } \\
\text { No statistically } \\
\text { significant } \\
\text { difference in } \\
\text { baseline } \\
\text { characteristics } \\
\text { before treatment }\end{array}$ & $\begin{array}{l}59 \text { patients } \\
\text { received: } \\
\text { LPV/RTV } \\
\text { (oral): } \\
\text { 200/50 mg } \\
\text { twice daily } \\
\text { for } 7 \text { days }\end{array}$ & $\begin{array}{l}36 \text { patients } \\
\text { received: } \\
\text { Umifenovi } \\
\text { r (oral): } \\
\text { 200mg } \\
\text { three times } \\
\text { daily for } 7 \\
\text { days } \\
\text { OR }\end{array}$ & $\begin{array}{l}\text { Time for the new coronavirus } \\
\text { nucleic acid in the pharyngeal } \\
\text { swab to turn negative was }(10.20 \\
\pm 3.49 \mathrm{~d}) \text { in LPV/RTV group, } \\
(10.11 \pm 4.68 \mathrm{~d}) \text { in umifenovir } \\
\text { group, }(10.86 \pm 4.74 \mathrm{~d}) \text { in } \\
\text { LPV/RTV plus umifenovir group, } \\
\text { and ( } 8.44 \pm 3.51 \mathrm{~d}) \text { in } \\
\text { conventional group } \\
\text { No significant difference in the } \\
\text { rate of nasopharyngeal swab new } \\
\text { coronavirus nucleic acid }\end{array}$ & $\begin{array}{l}\text { AEs in the three } \\
\text { groups of patients } \\
\text { using antiviral } \\
\text { drugs was } \\
\text { significantly higher } \\
\text { than that in the } \\
\text { conventional } \\
\text { treatment group } \\
\left(\chi^{2}=14.875 \text {, }\right. \\
\mathrm{p}=0.002)\end{array}$ & NOS, 5 & $\begin{array}{l}\text { All three } \\
\text { groups were } \\
\text { treated with } \\
\text { Standard } \\
\text { care* if in } \\
\text { need }\end{array}$ \\
\hline
\end{tabular}


Jun et al. 2020 [];

China
Retrospective;

cohort;

single center between patients i
LPV/RTV group,
umifenovir group
combination
(LPV/RTV and
umifenovir) group
and conventional
treatment (no
antiviral therapy)

antiviral the
group

Median

(IQR),

48 (35-

62)
69

(51.5)

\section{Confirmed COVID-}

19

cases

No statistically significant

differences in the demographic data, clinical

manifestations,

laboratory

examinations, and

chest CT

examination of

patients in the

LPV/RTV group

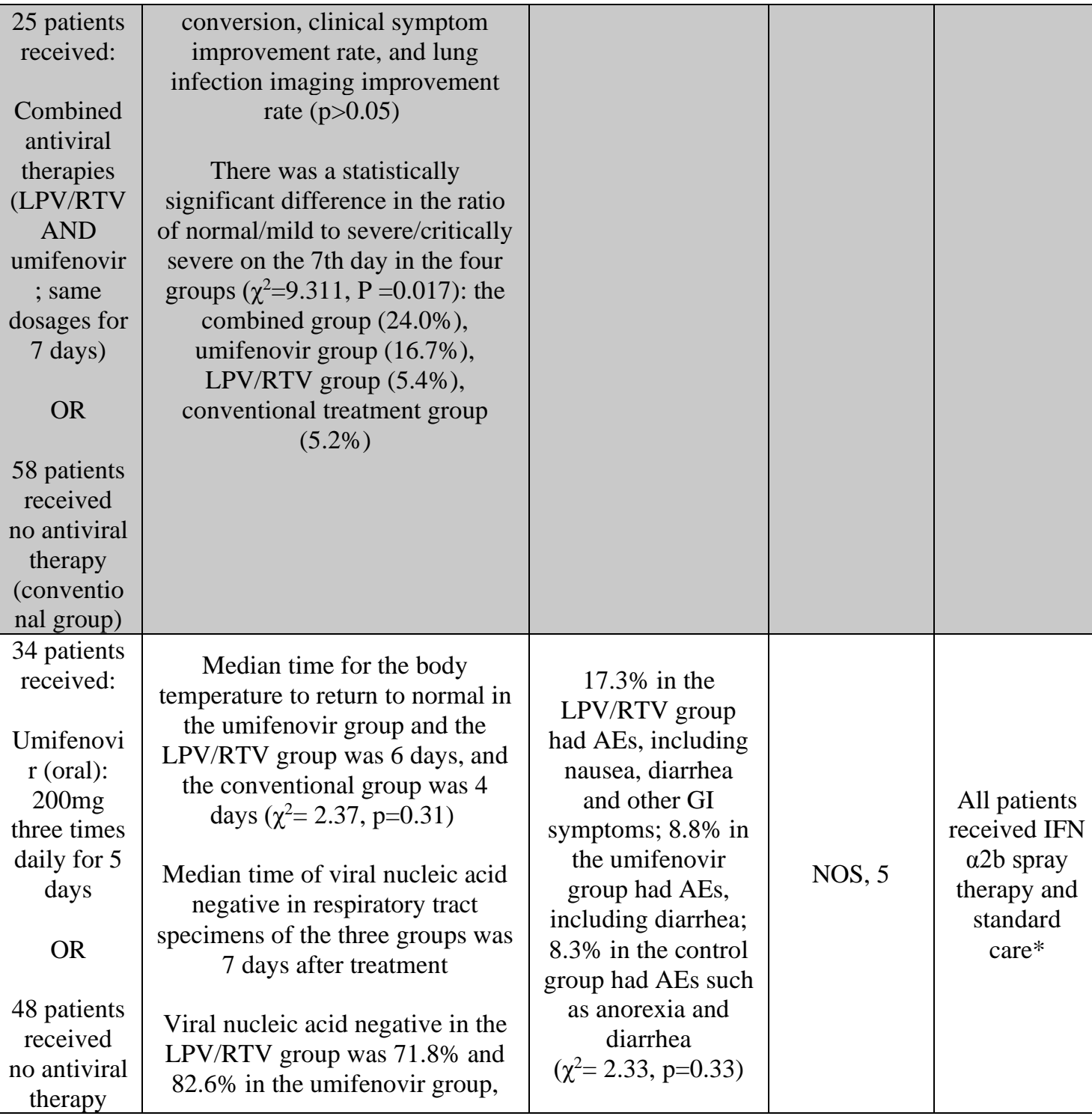




\begin{tabular}{|c|c|c|c|c|c|c|c|c|c|c|}
\hline & & & & $\begin{array}{l}\text { umifenovir group, } \\
\text { and control (no } \\
\text { antiviral therapy) } \\
\text { group (all } p>0.05 \text { ) }\end{array}$ & & $\begin{array}{l}\text { (conventio } \\
\text { nal group) }\end{array}$ & $\begin{array}{l}\text { the conventional group was } \\
77.1 \%\left(\chi^{2}=0.46, \mathrm{p}=0.79\right) \\
\text { 42.3\% patients in the LPV/RTV } \\
\text { group, 35.3\% patients in the } \\
\text { umifenovir group, and } 52.1 \% \\
\text { patients in the conventional group } \\
\text { still had progressive imaging on } \\
\text { the } 7 \text { th day after treatment } \\
\left(\chi^{2}=2.38, \mathrm{p}=0.30\right)\end{array}$ & & & \\
\hline $\begin{array}{l}\text { Yan et al. } \\
2020 \text { []; } \\
\text { China }\end{array}$ & $\begin{array}{l}\text { Retrospective; } \\
\text { cohort; } \\
\text { single center }\end{array}$ & $\begin{array}{c}\text { Median } \\
\text { (IQR), } \\
52(35- \\
63)\end{array}$ & $\begin{array}{c}54 \\
(45)\end{array}$ & $\begin{array}{l}\text { Confirmed COVID- } \\
19 \\
\text { cases and had the } \\
\text { available RNA viral } \\
\text { data to estimate the } \\
\text { duration of } \\
\text { viral shedding }\end{array}$ & $\begin{array}{l}78 \text { patients } \\
\text { received: } \\
\text { LPV/RTV } \\
\text { (oral): } \\
200 / 50 \mathrm{mg} \\
\text { twice daily } \\
\text { for } 10 \text { days } \\
\text { or more }\end{array}$ & $\begin{array}{l}42 \text { patients } \\
\text { received } \\
\text { no antiviral } \\
\text { therapy } \\
\text { (conventio } \\
\text { nal group) }\end{array}$ & $\begin{array}{c}\text { Median duration of viral shedding } \\
\text { was shorter in the LPV/RTV } \\
\text { treatment group than that in no } \\
\text { LPV/RTV treatment group } \\
\text { (median, } 22 \text { days vs. } 28.5 \text { days, } \\
\text { p=0.02) } \\
\text { Patients who started LPV/RTV } \\
\text { treatment within } 10 \text { days from } \\
\text { symptom onset had a shorter } \\
\text { duration of SARS-CoV-2 RNA } \\
\text { shedding than other patients who } \\
\text { began after } 10 \text { days (median } 19 \\
\text { days vs. } 27.5 \text { days, } p<0.001 \text { ) }\end{array}$ & Not reported & NOS, 5 & $\begin{array}{l}\text { Many } \\
\text { patients } \\
\text { received and } \\
\text { standard } \\
\text { care* if in } \\
\text { need }\end{array}$ \\
\hline $\begin{array}{l}\text { Yuan et al. } \\
2020 \text { []; } \\
\text { China }\end{array}$ & $\begin{array}{l}\text { Retrospective; } \\
\text { cohort; } \\
\text { single center }\end{array}$ & $\begin{array}{c}\text { Median } \\
\text { (range), } \\
40(1-78)\end{array}$ & $\begin{array}{c}42 \\
(45)\end{array}$ & $\begin{array}{l}\text { Confirmed COVID- } \\
19 \text { cases of mild } \\
\text { and/or moderate } \\
\text { symptoms and } \\
\text { critical conditions } \\
\\
\text { Significant different } \\
\text { illness onset on the } \\
\text { most common } \\
\text { symptoms (fever, } \\
\text { fatigue and } \\
\text { diarrhoea) }\end{array}$ & $\begin{array}{l}46 \text { patients } \\
\text { received: } \\
\text { IFN- } \alpha+ \\
\text { LPV/RTV } \\
\text { (dosages, } \\
\text { durations } \\
\text { were not } \\
\text { reported) }\end{array}$ & $\begin{array}{c}41 \text { patients } \\
\text { received: } \\
\text { IFN- } \alpha+ \\
\text { LPV/RTV } \\
\text { PLUS } \\
\text { Ribavirin; } \\
\text { (dosages, } \\
\text { durations } \\
\text { were not } \\
\text { reported) }\end{array}$ & $\begin{array}{c}\text { No significant difference on } \\
\text { average LOS or PCR negative } \\
\text { conversion times among different } \\
\text { antivirus treatment groups. } \\
\text { Correlation analysis indicated that } \\
\text { the duration of hospital stay was } \\
\text { significantly correlated with PCR } \\
\text { negative conversion } \\
\text { times in IFN- } \alpha+ \\
\text { lopinavir/ritonavir + ribavirin } \\
\text { group ( } \mathrm{p}=0.0215) \text {, as well as IFN- } \\
\alpha+\text { lopinavir/ritonavir group } \\
(\mathrm{p}=0.012)\end{array}$ & Not reported & NOS, 6 & $\begin{array}{c}\text { Approximate } \\
\text { ly } 51 \% \text { were } \\
\text { aged } \leq 40 \mathrm{y}, \\
\text { including } 2 \\
\text { children } \\
\text { under } 3 \mathrm{y}\end{array}$ \\
\hline
\end{tabular}




\begin{tabular}{|c|c|c|c|c|c|c|c|c|c|c|}
\hline & & & & & & & $\begin{array}{l}\text { Average LOS and IFN treatment } \\
\text { duration of moderate group were } \\
14.12(13.34-14.90) \text { days and } \\
14.24(13.45-15.03) \text { days, } \\
\text { respectively, while those of the } \\
\text { severe group took average } 2.08 \\
\text { days and 1.44 days longer }\end{array}$ & & & \\
\hline $\begin{array}{l}\text { Zhu et al. } \\
2020[] ; \\
\text { China }\end{array}$ & $\begin{array}{l}\text { Retrospective; } \\
\text { cohort; } \\
\text { multicenter }\end{array}$ & $\begin{array}{c}\text { Mean } \\
(\mathrm{SD}) \text {, } \\
39.8 \\
(17.6)\end{array}$ & $\begin{array}{c}26 \\
(52)\end{array}$ & $\begin{array}{l}\text { Confirmed COVID- } \\
19 \text { cases } \\
\\
\text { No significant } \\
\text { difference in age } \\
\text { and sex between the } \\
\text { two groups }\end{array}$ & $\begin{array}{l}34 \text { patients } \\
\text { received: } \\
\text { LPV/RTV } \\
\text { (oral): } \\
\text { 200/50 mg } \\
\text { twice daily } \\
\text { for } 7 \text { days }\end{array}$ & $\begin{array}{l}16 \text { patients } \\
\text { received: } \\
\text { Umifenovi } \\
\text { r (oral): } \\
\text { 200mg } \\
\text { three times } \\
\text { daily } \\
\text { (duration } \\
\text { was not } \\
\text { reported) }\end{array}$ & $\begin{array}{l}\text { No difference in fever duration } \\
\text { between the two groups ( } \mathrm{p}=0.61 \text { ) } \\
\text { On day } 14 \text { after the admission, no } \\
\text { viral load was detected in } \\
\text { umifenovir group, but the viral } \\
\text { load was found in } 44.1 \% \text { patients } \\
\text { treated with LPV/RTV } \\
\text { Patients in the umifenovir group } \\
\text { had a shorter duration of positive } \\
\text { RNA test compared to those in } \\
\text { the LPV/RTV group ( } \mathrm{p}<0.01)\end{array}$ & $\begin{array}{l}\text { No apparent SEs } \\
\text { were found in both } \\
\text { groups }\end{array}$ & NOS, 6 & $\begin{array}{l}\text { All patients } \\
\text { received and } \\
\text { standard } \\
\text { care* if in } \\
\text { need }\end{array}$ \\
\hline $\begin{array}{l}\text { Ye et al. } \\
2020[] \\
\text { China }\end{array}$ & $\begin{array}{l}\text { Retrospective; } \\
\text { cohort; } \\
\text { single center }\end{array}$ & $\begin{array}{c}\text { Range } \\
(5-68) \text {, of } \\
\text { which } 9 \\
\text { were }<30 \\
\text { and } 38 \\
\text { were }>30\end{array}$ & $\begin{array}{c}22 \\
(46.8)\end{array}$ & $\begin{array}{l}\text { Confirmed COVID- } \\
19 \text { cases treated } \\
\text { with LPV/RTV or } \\
\text { not during } \\
\text { hospitalization } \\
\text { Different age, sex, } \\
\text { and baseline } \\
\text { demographics in } \\
\text { each group }\end{array}$ & $\begin{array}{l}42 \text { patients } \\
\text { received: } \\
\text { LPV/RTV } \\
\text { (oral): } \\
400 / 100 \mathrm{mg} \\
\text { twice daily } \\
\text { or } 800 / 200 \\
\text { mg once } \\
\text { daily } \\
\text { PLUS } \\
\text { Umifenovir } \\
\text { (oral): }\end{array}$ & $\begin{array}{l}5 \text { patients } \\
\text { received: } \\
\text { Umifenovi } \\
\text { r (oral): } \\
200 \mathrm{mg} \\
\text { three times } \\
\text { daily } \\
\text { PLUS } \\
\text { IFN- } \alpha 1 \mathrm{~b} \\
\text { (aerosol } \\
\text { inhalation) } \\
:\end{array}$ & $\begin{array}{l}\text { Patients in the LPV/RTV group } \\
\text { returned to normal body } \\
\text { temperature in a shorter time (test } \\
\text { group: } 4.8 \pm 1.94 \text { days vs. control } \\
\text { group: } 7.3 \pm 1.53 \text { days, } \mathrm{p}=0.0364 \text { ) } \\
\\
\text { Patients in the LPV/RTV group } \\
\text { were able to turn negative in a } \\
\text { shorter period of time (LPV/RTV } \\
\text { group: } 7.8 \pm 3.09 \text { days vs. control } \\
\text { group: } 12.0 \pm 0.82 \text { days, } \mathrm{p}=0.0219 \text { ) }\end{array}$ & $\begin{array}{l}\text { Increased level of } \\
\text { ALT enzyme in the } \\
\text { LPV/RTV group }\end{array}$ & NOS, 5 & $\begin{array}{l}\text { All patients } \\
\text { received and } \\
\text { standard } \\
\text { care* if in } \\
\text { need }\end{array}$ \\
\hline
\end{tabular}




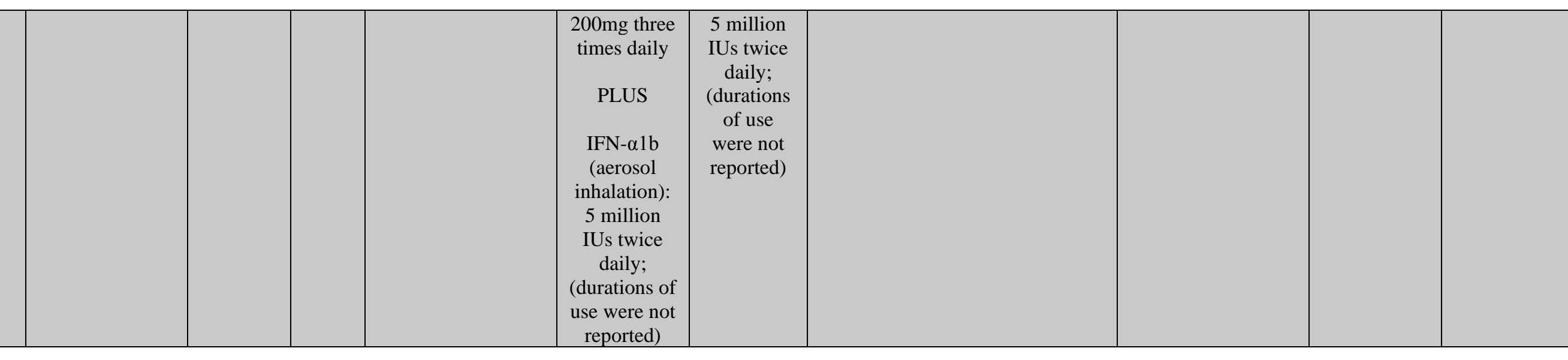

Abbreviations: AEs, adverse events; ALT, alanine aminotransferase; COVID-19, coronavirus disease 2019; CT, computed tomography; FiO2, fraction of inspired oxygen; FPV, favipiravir; GI, gastrointestinal; IFN, interferon; IQR, interquartile range; ITT, intention-to-treat; IUs, international units; LOS, length of hospital stay; LPV/RTV, lopinavir/ritonavir; NA, not applicable; NEWS2, National Early Warning Score 2; NHC, National Health Commission of China; NOS, Newcastle Ottawa Scale; $\mathrm{PaO} 2$, partial pressure of oxygen; RoB 2, Version 2 of the Cochrane risk-of-bias tool for randomized trials; ROBINS-I, Risk of bias in non-randomized studies of interventions; RT-PCR, real-time reverse transcription-polymerase chain reaction; SaO2, oxygen saturation; SARS-CoV-2, severe acute respiratory syndrome coronavirus 2; SCI, subcutaneous injection; SEs, side effects

*Standard care comprised, as necessary, supplemental oxygen, noninvasive and invasive ventilation, antibiotic agents, vasopressor support, renal-replacement therapy, and extracorporeal membrane oxygenation (ECMO). 
medRxiv preprint doi: https://doi.org/10.1101/2020.06.16.20133298; this version posted June 19, 2020. The copyright holder for this preprint (which was not certified by peer review) is the author/funder, who has granted medRxiv a license to display the preprint in perpetuity.

It is made available under a CC-BY-NC-ND 4.0 International license.

\section{Comparison 1: efficacy and safety of lopinavir/ritonavir versus no antiviral therapy (conventional therapy) or control}

A total of six studies (23-28) reported on lopinavir/ritonavir versus no antiviral therapy (conventional therapy) or control $(n=594)$ in terms of efficacy and safety.

\section{A. Virological cure on day 7 post initiation of therapy (+ve to -ve PCR: nondetection of SARS-CoV-2 in nasopharyngeal swab):}

1. Lopinavir/ritonavir versus no antiviral therapy (conventional cure): virologic cure at day 7 post initiation of therapy:

Three studies reported a virologic cure $(\mathrm{n}=171$ in lopinavir/ritonavir alone $\operatorname{arm}$ vs $\mathrm{n}=$

117 in conventional arm) on day $7(23,25,28)$. Significant mean difference was observed between the two arms in terms of virological cure (mean difference $=-0.81$ day; $95 \% \mathrm{CI}$, -4.44 to $2.81 ; P=0.007, I^{2}=80 \%$ ) (Figure 1.1 ).

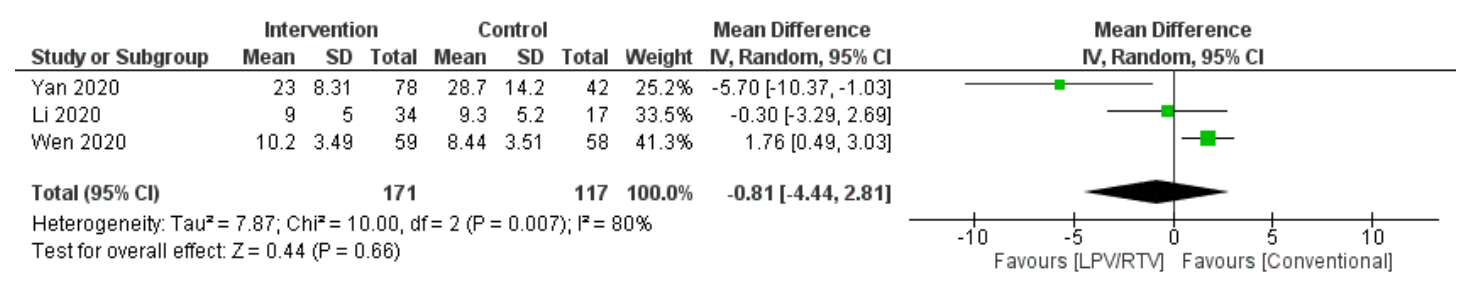

Figure 1.1: Time from +ve to -ve PCR (days) (LPV/RTV vs no antiviral treatment or conventional). CI, confidence interval; df, degrees of freedom; lopinavir/ritonavir (LPV/RTV) 
medRxiv preprint doi: https://doi.org/10.1101/2020.06.16.20133298; this version posted June 19, 2020. The copyright holder for this preprint (which was not certified by peer review) is the author/funder, who has granted medRxiv a license to display the preprint in perpetuity.

It is made available under a CC-BY-NC-ND 4.0 International license .

2. Lopinavir/ritonavir vs umifenovir: Virologic cure at day 7 post initiation of therapy:

Three studies reported on virological cure $(n=127$ in lopinavir/ritonavir alone arm vs $n=$ 87 in umifenovir arm) on day $7(23,26,28)$. No significant mean difference was observed between the two arms in terms of virological cure (mean difference $=0.95$ day; 95\% CI, -1.11 to $3.01 ; P=0.09, I^{2}=58 \%$ ) (Figure 1.2 ).

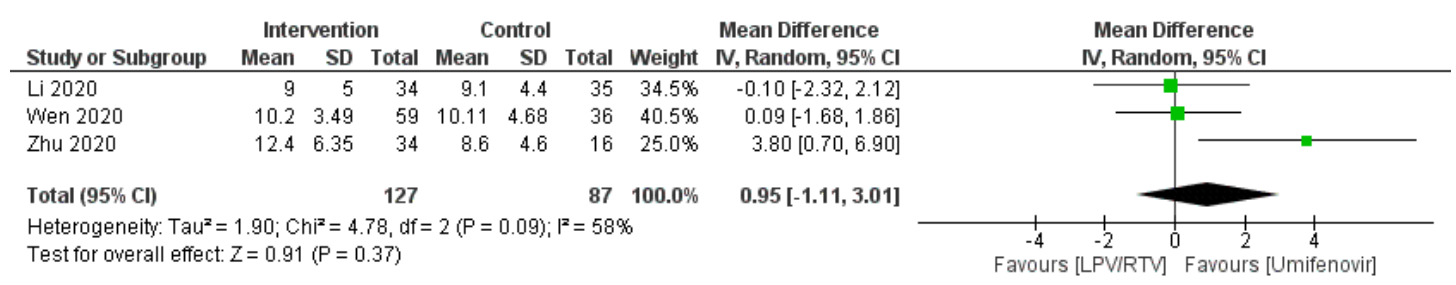

Figure 1.2: Time from +ve to -ve PCR (days) (LPV/RTV vs umifenovir). CI, confidence interval; df, degrees of freedom; LPV/RTV, lopinavir/ritonavir

3. Lopinavir/ritonavir vs umifenovir plus lopinavir/ritonavir: Virologic cure at day 7 post initiation of therapy:

Two studies reported on virological cure $(n=93$ in lopinavir/ritonavir alone arm vs $n=$ 75 in umifenovir plus lopinavir/ritonavir arm) on day $7(24,28)$. No significant mean difference was observed between the two arms in terms of virological cure (mean difference $=-0.83$ day; $95 \% \mathrm{CI},-2.45$ to $\left.0.78 ; P=0.66, I^{2}=0 \%\right)($ Figure 1.3$)$.

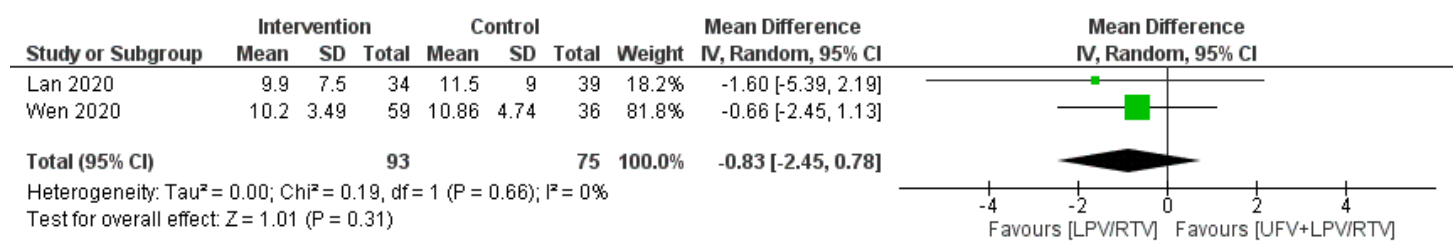

Figure 1.3: Time from +ve to -ve PCR (days) (LPV/RTV vs LPV/RTV plus umifenovir combination). CI, confidence interval; df, degrees of freedom; LPV/RTV, lopinavir/ritonavir; UFV, umifenovir 
medRxiv preprint doi: https://doi.org/10.1101/2020.06.16.20133298; this version posted June 19, 2020. The copyright holder for this preprint (which was not certified by peer review) is the author/funder, who has granted medRxiv a license to display the preprint in perpetuity.

It is made available under a CC-BY-NC-ND 4.0 International license .

\section{B. Clinical cure (time to body temperature normalization and time to cough relief)}

\section{Time to body temperature normalization}

\subsection{Lopinavir/ritonavir vs umifenovir:}

Two studies reported on time to temperature normalization $(n=93$ in lopinavir/ritonavir alone arm vs $n=71$ in umifenovir arm) $[23,28]$. No significant association was observed between the two arms in terms of temperature normalization $(\mathrm{OR}=0.87$ day; $95 \% \mathrm{CI}$,

0.42 to $1.78 ; P=0.61, I^{2}=0 \%$ ) (Figure 1.4$)$.

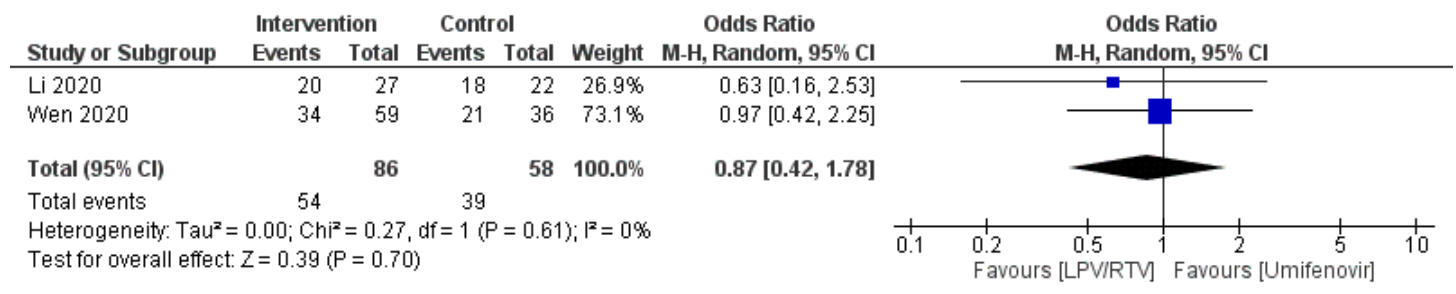

Figure 1.4: Time to body temperature normalization (days) (LPV/RTV vs umifenovir). CI, confidence interval; df, degrees of freedom; LPV/RTV, lopinavir/ritonavir

1.2 Lopinavir/ritonavir versus no antiviral therapy (conventional):

Two studies reported on time to temperature normalization $(n=93$ in lopinavir/ritonavir alone arm vs $n=75$ in conventional arm) $[23,28]$. No significant association was observed between the two arms in terms of temperature normalization $(\mathrm{OR}=0.99$ day; $95 \% \mathrm{CI}, 0.49$ to $\left.1.99, P=0.35, I^{2}=0 \%\right)($ Figure 1.5$)$.

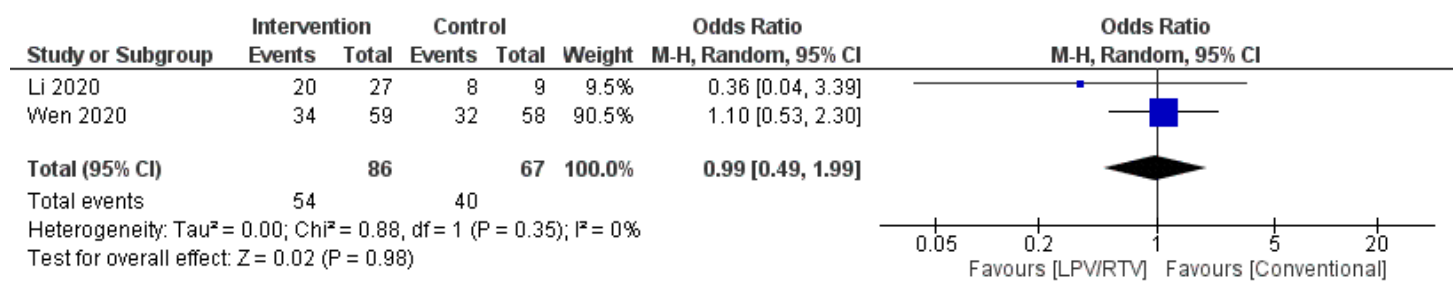

Figure 1.5: Time to body temperature normalization (days) (LPV/RTV vs no antiviral treatment or conventional). CI, confidence interval; df, degrees of freedom; LPV/RTV, lopinavir/ritonavir 
medRxiv preprint doi: https://doi.org/10.1101/2020.06.16.20133298; this version posted June 19, 2020. The copyright holder for this preprint (which was not certified by peer review) is the author/funder, who has granted medRxiv a license to display the preprint in perpetuity.

It is made available under a CC-BY-NC-ND 4.0 International license .

\section{Duration of cough}

2.1 Lopinavir/ritonavir versus umifenovir: Rate of cough alleviation after 7 days of therapy:

Two studies reported on cough alleviation $(n=93$ in lopinavir/ritonavir alone arm vs $n=$ 71 in umifenovir arm) $(23,28)$. Lopinavir/ritonavir alone arm had a significant lower number of cough days by 0.62 (95\% CI 0.06 to $6.53, P=0.02 ; I^{2}=81 \%$ ) (Figure 1.6).

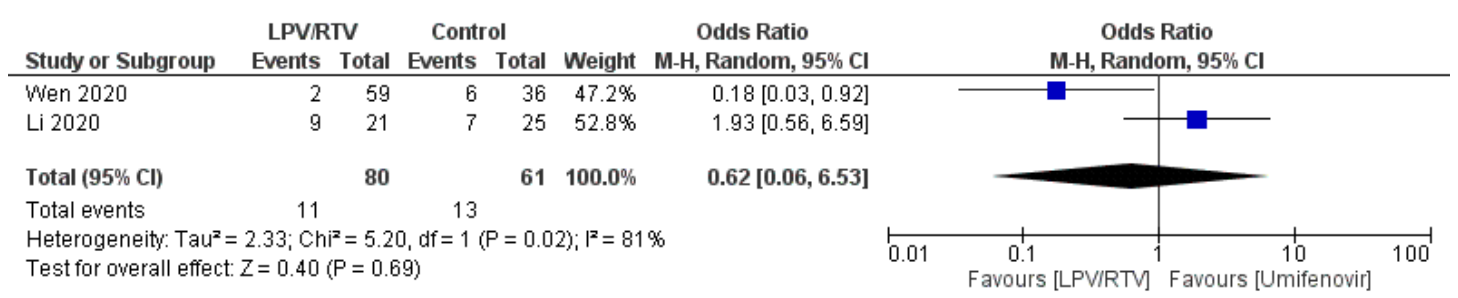

Figure 1.6: Rate of cough alleviation after 7 days of treatment (LPV/RTV vs umifenovir). CI, confidence interval; df, degrees of freedom; LPV/RTV, lopinavir/ritonavir

2.2 Lopinavir/ritonavir vs no antiviral therapy (conventional): Rate of cough alleviation after 7 days of therapy:

Two studies reported on cough alleviation $(n=93$ in lopinavir/ritonavir alone arm vs $n=$ 75 in conventional arm) $(23,28)$. No significant association was observed between the two arms in terms of cough alleviation $\left(\mathrm{OR}=0.87\right.$ day; $95 \% \mathrm{CI}, 0.10$ to $7.16 ; P=0.08, I^{2}$ $=67 \%)($ Figure 1.7).

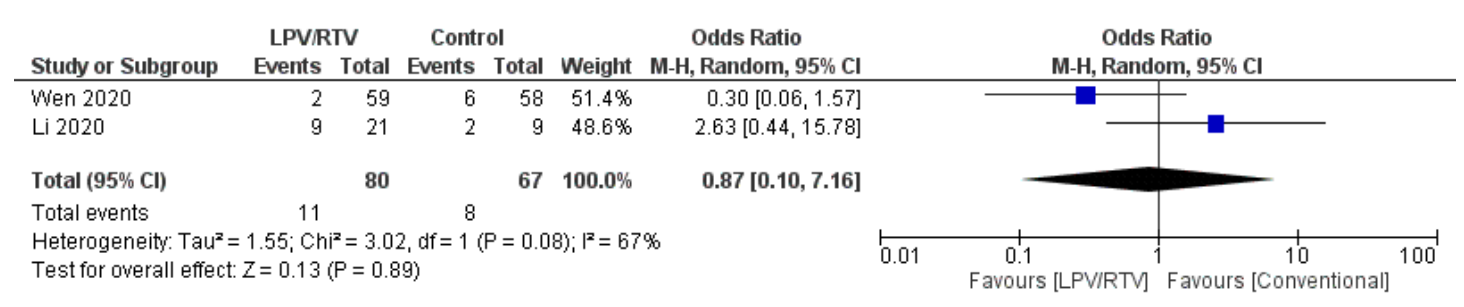

Figure 1.7: Rate of cough alleviation after 7 days of treatment (LPV/RTV vs no antiviral treatment or conventional). CI, confidence interval; df, degrees of freedom; LPV/RTV, lopinavir/ritonavir 
medRxiv preprint doi: https://doi.org/10.1101/2020.06.16.20133298; this version posted June 19, 2020. The copyright holder for this preprint (which was not certified by peer review) is the author/funder, who has granted medRxiv a license to display the preprint in perpetuity.

It is made available under a CC-BY-NC-ND 4.0 International license .

\section{Radiological progression during drug treatment}

1. Rate of improvement on chest $\mathrm{CT}$ after 7 days of treatment:

\subsection{Lopinavir/ritonavir vs umifenovir:}

In terms of CT evidence of radiological progression of pneumonia/lung damage $(\mathrm{n}=59$

in the lopinavir/ritonavir arm vs $\mathrm{n}=71$ in umifenovir arm), treatment with

lopinavir/ritonavir resulted in no significant decrease in the radiological progression (OR

$=0.80 ; 95 \%$ CI, 0.42 to $\left.1.54 ; P=0.59, I^{2}=81 \%\right)($ Figure 1.8$)$.

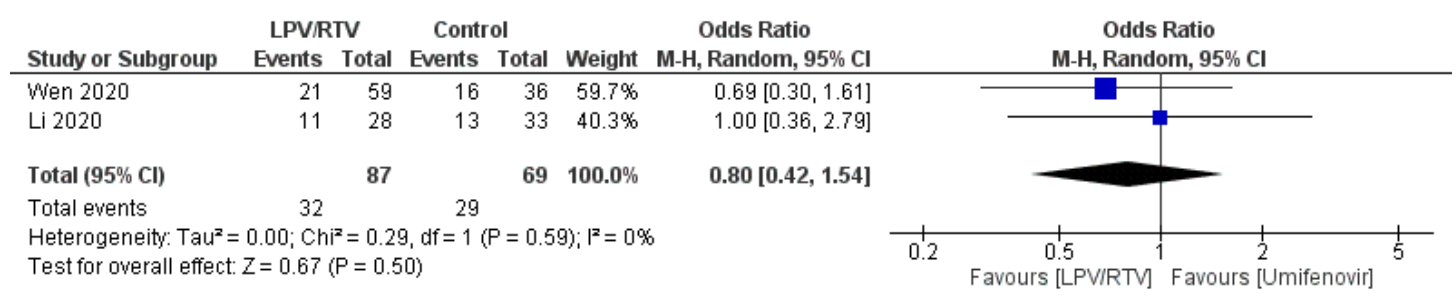

Figure 1.8: Rate of improvement on chest CT after 7 days of treatment (LPV/RTV vs umifenovir). CI, confidence interval; df, degrees of freedom; LPV/RTV, lopinavir/ritonavir

\subsection{Lopinavir/ritonavir vs no antiviral therapy (conventional):}

In terms of CT evidence of radiological progression of pneumonia/lung damage ( $\mathrm{n}=71$

in the lopinavir/ritonavir arm vs $n=75$ in conventional arm), treatment with

lopinavir/ritonavir resulted in no significant decrease in the radiological progression (OR $=0.69 ; 95 \% \mathrm{CI}, 0.36$ to $\left.1.31 ; P=0.42, I^{2}=0 \%\right)($ Figure 1.9$)$.

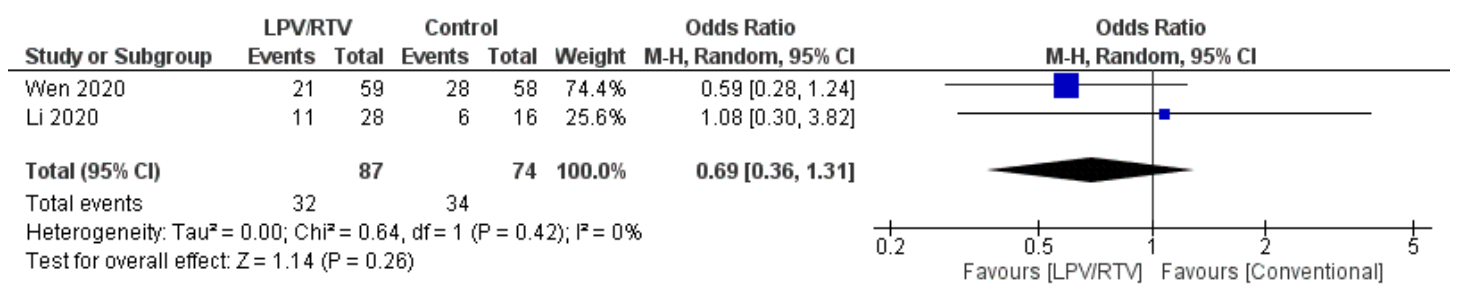

Figure 1.9: Rate of improvement on chest CT after 7 days of treatment (LPV/RTV vs no antiviral treatment or conventional). CI, confidence interval; df, degrees of freedom; LPV/RTV, lopinavir/ritonavir 
medRxiv preprint doi: https://doi.org/10.1101/2020.06.16.20133298; this version posted June 19, 2020. The copyright holder for this preprint (which was not certified by peer review) is the author/funder, who has granted medRxiv a license to display the preprint in perpetuity.

It is made available under a CC-BY-NC-ND 4.0 International license .

\section{Safety and tolerability}

1.1 Rate of adverse events of treatment: Lopinavir/ritonavir vs umifenovir:

A greater number of adverse events were reported for lopinavir/ritonavir $(n=45)$ relative

to the umifenovir arm $(\mathrm{n}=14)\left(\mathrm{OR}=2.66 ; 95 \% \mathrm{CI}, 1.36\right.$ to $5.19 ; P=0.004, I_{2}=0 \%$;

Figure 1.10).

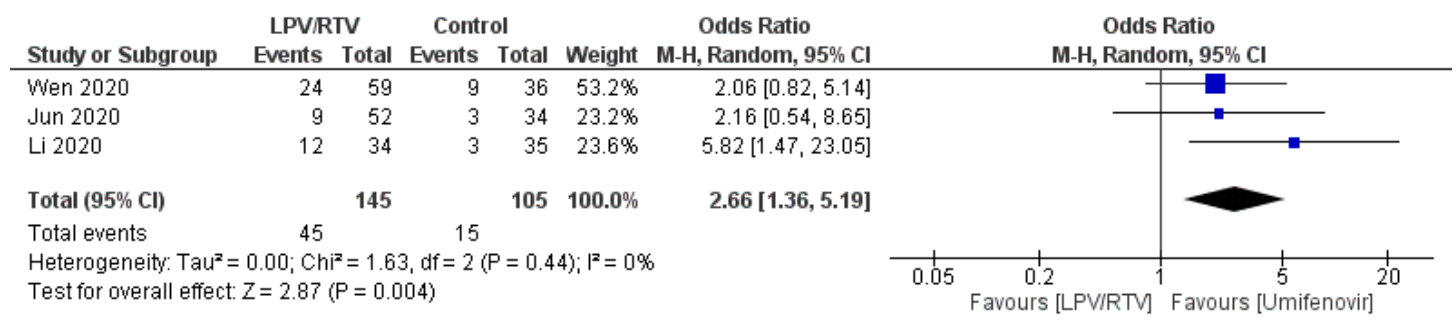

Figure 1.10: Rate of adverse events of treatment (LPV/RTV vs umifenovir). CI, confidence interval; df, degrees of freedom; LPV/RTV, lopinavir/ritonavir

1.2 Rate of adverse events of treatment: Lopinavir/ritonavir versus no antiviral treatment (conventional):

A greater number of adverse events were reported lopinavir/ritonavir $(n=45)$ than antiviral treatment or conventional $(\mathrm{n}=10)(P=0.0007)($ Figure 1.11).

Figure 1.11 Rate of adverse events of treatment (LPV/RTV vs no antiviral treatment or

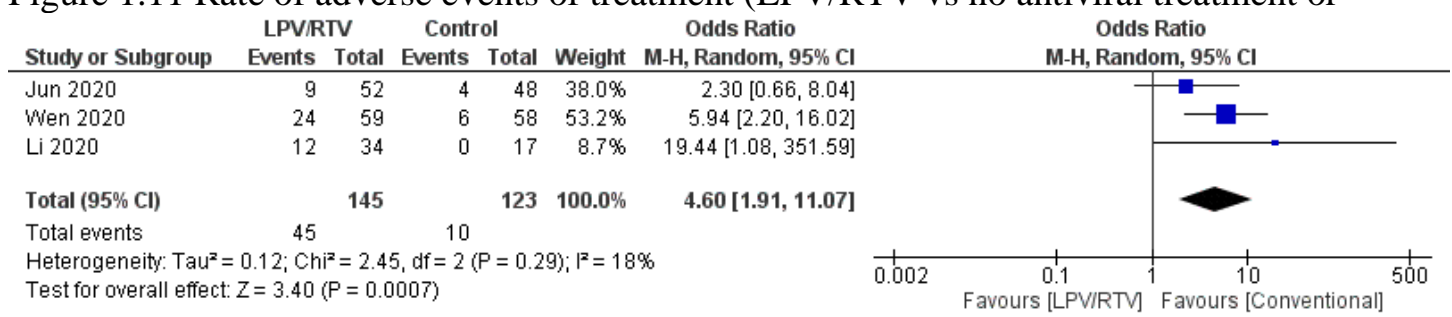

conventional). CI, confidence interval; df, degrees of freedom; LPV/RTV, lopinavir/ritonavir 
medRxiv preprint doi: https://doi.org/10.1101/2020.06.16.20133298; this version posted June 19, 2020. The copyright holder for this preprint (which was not certified by peer review) is the author/funder, who has granted medRxiv a license to display the preprint in perpetuity.

It is made available under a CC-BY-NC-ND 4.0 International license .

\section{Comparison 2: Efficacy and safety of lopinavir/ritonavir along in combination with other agents versus no antiviral therapy (conventional therapy) or control}

A total of four studies evaluated efficacy of LPV/RTV plus interferon (IFN) [29-32] and three studies [29-31] evaluated the safety of the combination. Other studies evaluated the efficacy of LPV/RTV plus standard care [12], ribavirin [30], or umifenovir [31], and evaluated safety of these combinations.

In terms of the efficacy of the combination in patients with COVID-19, LPV/RTV plus IFN combination in addition to ribavirin was safe and superior to LPV/RTV alone by shortening median time from start of study treatment to negative nasopharyngeal swab (7 days [IQR 5-11]) compared to the LPV/RTV arm (12 days [8-15]; hazard ratio 4.37 [95\% CI 1.86-10·24], $\mathrm{p}=0 \cdot 001)(30)$. Additionally, combination treatment with LPV/RTV plus IFN and umifenovir had a more evident therapeutic effect in a shorter time by normalizing body temperature $(4.8 \pm 1.94$ days vs. $7.3 \pm 1.53$ days, $\mathrm{p}=0.03)$ and turning PCRs to negative $(7.8 \pm 3.09$ days vs. $12.0 \pm 0.82$ days, $\mathrm{p}=0.02)$ compared to the umifenovir plus IFN arm with no evident toxic and side effects [31]. However, the use of LPV/RTV plus IFN combination resulted in less therapeutic responses on COVID-19 in terms of viral clearance [median (interquartile range, IQR), 4 (2.5-9) d versus 11 (8-13) $\mathrm{d}, \mathrm{p}<0.001)$ and chest CT changes (91.43\% vs $62.22 \%), \mathrm{p}=0.004]$ compared to the favipiravir plus IFN combination. Favipiravir arm patients had less adverse events (AEs) compared to the LPV/RTV arm $(11.43 \%$ vs $55.56 \%)(\mathrm{p}<0.001)(29)$. Additionally, no significant difference on average PCR negative conversion times among IFN plus LPV/RTV or IFN plus LPV/RTV plus ribavirin treatment arms [32]. 
medRxiv preprint doi: https://doi.org/10.1101/2020.06.16.20133298; this version posted June 19, 2020. The copyright holder for this preprint (which was not certified by peer review) is the author/funder, who has granted medRxiv a license to display the preprint in perpetuity.

It is made available under a CC-BY-NC-ND 4.0 International license .

The combination of LPV/RTV, in addition to standard care, or standard care alone exhibited no difference in the time to clinical improvement (hazard ratio for clinical improvement, $1.31 ; 95 \% \mathrm{CI}, 0.95$ to 1.80$)$ with a similar 28 -day mortality (19.2\% vs. $25.0 \%$; difference, -5.8 percentage points; $95 \% \mathrm{CI},-17.3$ to 5.7$)$.

\section{Discussion}

This systematic review included 11 articles relating to the efficacy and safety of lopinavir/ritonavir in COVID-19 patients, with a total of 1,192 patients included, and only six articles that comprised 594 patients had findings on the efficacy and safety of lopinavir/ritonavir in treatment of COVID-19 verses control/conventional therapy were deemed legible for quantitative synthesis (meta-analysis) [23-28].

In terms of virological cure, three studies reported less time in days for LPV/RTV arm (n = 171) compared with no antiviral therapy (conventional) $(n=117)$; however, the overall effect was not significant (mean difference $=-0.81$ day; $95 \% \mathrm{CI},-4.44$ to $2.81 ; P=$ 0.66), similarly the virological cure for lopinavir/ritonavir alone $(n=127)$ versus the umifenovir arm $(\mathrm{n}=87)(P=0.37)$, or lopinavir/ritonavir versus umifenovir plus lopinavir/ritonavir $(P=0.31)[23-28]$.

Two studies reported on time to temperature normalization with no significant effect of LPV/RTV $(\mathrm{n}=93)$ versus umifenovir $(\mathrm{n}=71)$ arm $),(\mathrm{OR}=0.87$ day; $95 \%$ CI, 0.42 to 1.78; $\left.(P=0.70), \mathrm{I}_{2}=0 \%\right)$, or alleviation of cough duration $(\mathrm{p}=0.69)[23,28]$. The total number of cough days was found to be lower in the LPV/RTV arm compared with the umifenovir arm or no antiviral therapy (conventional) arm after 7 days of treatment; however, the overall effect was found to be not significant [23,28]. 
medRxiv preprint doi: https://doi.org/10.1101/2020.06.16.20133298; this version posted June 19, 2020. The copyright holder for this preprint

Interestingly in this study, treatment with lopinavir/ritonavir $(n=93)$ versus umifenovir plus lopinavir/ritonavir $(\mathrm{n}=75)$ arm did not reveal any significant mean difference between the two arms in terms of virological cure at day seven. In contrast, a favorable therapeutic effect for umifenovir was observed in a small cohort study when the drug was combined with lopinavir/ritonavir treatment in sixteen COVID-19 patients rather than lopinavir/ritonavir alone $(\mathrm{n}=17)$ [33].

In another study that involved 81 COVID-19 patients, the umifenovir treatment group had a longer hospital stay than patients in the control group (13 days (IQR 9-17) vs 11 days (IQR 9-14), p 0.04) [34].

Of note, umifenovir, which is branded as Arbidol®, has a wide antiviral activity against RNA and DNA viruses, and is licensed in Russia and China for treatment and prophylaxis of influenza, is recommended for treatment of MERS-CoV, was investigated in SARS-CoV, and is currently being trialed in COVID-19 patients [35].

In terms of CT evidence of radiological progression of pneumonia/lung damage of lopinavir/ritonavir arm versus umifenovir, although a fewer number of patients exhibited radiological progression in the LPV/RTV arm compared with the umifenovir arm or no antiviral therapy (conventional) arm after 7 days of treatment, this effect was not significant $(P=0.59)$. Similarly, with lopinavir/ritonavir $(n=71)$ versus no antiviral therapy $[23,28]$.

In terms of safety, this study found greater adverse events reported in lopinavir/ritonavir arm versus no antiviral treatment (conventional) or umifenovir respectively.

Adverse events associated with lopinavir-ritonavir alone or in combination with other medicines were reported in COVID-19 patients, and were typically gastrointestinal (GIT) 
medRxiv preprint doi: https://doi.org/10.1101/2020.06.16.20133298; this version posted June 19, 2020. The copyright holder for this preprint

in nature, including nausea, vomiting, and diarrhea [28]; however, serious GIT ADRs such as acute gastritis and GIT bleeding and acute kidney injury $(n=3)$ were also reported (28). It was reported that most ADRs associated with lopinavir-ritonavir in combined groups of medicines are resolved within three days of drug initiation [29].

To address the efficacy and safety of LPV/RTV combined with other drugs in patients with COVID-9, LPV/RTV plus IFN combination in addition to ribavirin was found superior and more safe than LPV/RTV alone by shortening time to negative nasopharyngeal swab compared to the LPV/RTV arm alone [30]. Additionally, a combined treatment regimen of LPV/RTV plus IFN and umifenovir resulted in a shorter time by normalizing body temperature and turning PCRs to negative compared to the umifenovir plus IFN arm with reasonable safety profile [31]. However, the use of LPV/RTV plus IFN combination resulted in less therapeutic responses on COVID-19 in terms of viral clearance and chest CT changes compared to the favipiravir plus IFN combination. Favipiravir arm patients had less AEs compared to the LPV/RTV arm [29]. Additionally, there was no significant difference in average PCR negative conversion times among IFN plus LPV/RTV or IFN plus LPV/RTV plus ribavirin treatment arms [32]. The combination of LPV/RTV, in addition to standard care, or standard care alone revealed no difference in the time to clinical improvement with a similar 28-day mortality. Gastrointestinal AEs were more common in the LPV/RTV arm, but serious AEs were more common in the standard care arm and treatment was stopped early in $13.8 \%$ of patients because of AEs [12].

In a recent systematic review (preprint version) that included 69 studies which included therapeutics for COVID-19, lopinavir/ritonavir was found to be the third therapeutic associated with positive outcomes (54.9\%) with less negative outcomes $(12.3 \%)$ compared 
medRxiv preprint doi: https://doi.org/10.1101/2020.06.16.20133298; this version posted June 19, 2020. The copyright holder for this preprint

to systemic corticosteroids (21.3\%), remdesivir (16.9\%), moxioxacin $(13.4 \%)$ and oseltamivir (12.5\%) [36]; however, further controlled studies are needed to draw a valid conclusion.

The key limitations of this study were the limited number of clinical studies investigating the efficacy and safety of lopinavir/ritonavir combination with the limited number of participants. Another limitation is inability to perform any type of meta-analysis specifically for the results of efficacy and safety of using lopinavir/ritonavir in combination with other agents versus no antiviral therapy (conventional therapy) or control because of the large methodological differences. Despite these limitations, this systematic review provided valuable insight into the efficacy, safety, and clinical outcomes of lopinavir/ritonavir alone or with other antiviral medications.

\section{Conclusions}

The small number of studies included in this systematic review and meta-analysis study did not reveal any statistically significant advantage in efficacy of lopinavir-ritonavir in COVID-19 patients, over conventional or other antiviral treatments. In terms of safety, this study found greater number of adverse events reported in lopinavir/ritonavir arm versus no antiviral treatment (conventional) or umifenovir arms respectively.

There is a general understanding of the need to conduct large randomized clinical trials to determine the efficacy and safety of lopinavir-ritonavir in the treatment of COVID-19. Ideally, these studies should be double-blinded and conducted in a range of settings. 
medRxiv preprint doi: https://doi.org/10.1101/2020.06.16.20133298; this version posted June 19, 2020. The copyright holder for this preprint (which was not certified by peer review) is the author/funder, who has granted medRxiv a license to display the preprint in perpetuity.

It is made available under a CC-BY-NC-ND 4.0 International license.

\section{Conflicts of interest}

The authors have no conflicts of interest relevant to this article.

\section{Funding}

No funding to declare. 
medRxiv preprint doi: https://doi.org/10.1101/2020.06.16.20133298; this version posted June 19, 2020. The copyright holder for this preprint (which was not certified by peer review) is the author/funder, who has granted medRxiv a license to display the preprint in perpetuity.

\section{References}

1- Yang, W., Cao, Q., Qin, L., Wang, X., Cheng, Z., Pan, A., et al. Clinical characteristics and imaging manifestations of the 2019 novel coronavirus disease (COVID-19): a multi-center study in Wenzhou city, Zhejiang, China [published online ahead of print, 2020 Feb 26]. J Infect, S0163-4453 (20) (2020), pp. 3009930102, 10.1016/j.jinf.2020.02.016

2- Tobaiqy, M., Qashqary, M., Al-Dahery, S., Mujallad, A, Hershan, A.A., Kamal, M.A., Helmi, N. Therapeutic management of COVID-19 patients: a systematic review. Infect Prev Pract. 2020:100061. doi: 10.1016/j.infpip.2020.100061

3- Statista. number of coronavirus (COVID-19) clinical trials for drugs and vaccines worldwide as of June 2, 2020, by typehttps://www.statista.com/statistics/1119086/coronavirus-drug-trials-by-typeworldwide/(last accessed on June 24, 2020).

4- Mehra, M.R., Desai, S.S., Ruschitzka, F., Patel, A.N. Hydroxychloroquine or chloroquine with or without a macrolide for treatment of COVID-19: a multinational registry analysis. Lancet 2020; (published online May 22). https://doi.org/10.1016/S0140-6736(20)31180-6

5- Retraction: "Hydroxychloroquine or chloroquine with or without a macrolide for treatment of COVID-19: a multinational registry analysis" https://www.thelancet.com/lancet/article/s0140673620313246?utm_campaign=tlp r\&utm_medium $=$ email\&_hsmi=89003655\&_hsenc=p2ANqtz8NWjheFKX817kgd7T7pso_ce9R0j8eBwSbn_H5wraOnc881NuGc24xZRAr0vySICqNUR1Nd3VEcShH2aaX9rECxNs_A\&utm_content=8 9003655\&utm_source=hs_email

6- BBC News. Trials to resume of anti-viral touted by trump. https://www.bbc.com/news/live/world-52900960 (last accessed on 24 June 2020).

7- Cvetkovic, R.S., Goa, K.L. Lopinavir/ritonavir: a review of its use in the management of HIV infection. Drugs. 2003;63(8): pp. 769-802. doi:10.2165/00003495-200363080-00004

8- Chan, K.S., Lai, S.T., Chu, C.M., et al. Treatment of severe acute respiratory syndrome with lopinavir/ritonavir: a multicentre retrospective matched cohort study. Hong Kong Med J. 2003;9(6): pp. 399-406. 
medRxiv preprint doi: https://doi.org/10.1101/2020.06.16.20133298; this version posted June 19, 2020. The copyright holder for this preprint (which was not certified by peer review) is the author/funder, who has granted medRxiv a license to display the preprint in perpetuity.

It is made available under a CC-BY-NC-ND 4.0 International license .

9- Chan, J.F., Yao, Y., Yeung M.L., et al. Treatment with Lopinavir/Ritonavir or Interferon- $\beta 1 \mathrm{~b}$ Improves Outcome of MERS-CoV Infection in a Nonhuman Primate Model of Common Marmoset. J Infect Dis. 2015;212(12):1904-1913. doi:10.1093/infdis/jiv392

10- Alhumaid, S., Tobaiqy, M., Albagshi, M., et al. MERS-CoV transmitted from animal-to-human vs MERSCoV transmitted from human-to-human: comparison of virulence and therapeutic outcomes in a Saudi hospital. Trop J Pharm Res, 17 (2018), Article 1155

11- Alhazzani, W., Møller, M.H., Arabi, Y.M., et al. Surviving Sepsis Campaign: guidelines on the management of critically ill adults with Coronavirus Disease 2019 (COVID-19). Intensive Care Med. 2020:1-34. https://doi.org/10.1097/CCM.0000000000004363

12- Cao, B., Wang, Y., Wen, D., et al. A Trial of Lopinavir-Ritonavir in Adults Hospitalized with Severe Covid-19. N Engl J Med. 2020;382(19):1787-1799. doi:10.1056/NEJMoa2001282

13- Massachusetts General HospitalCOVID-19 treatment guidance. MGH, Boston (2020). Available at: https://www.massgeneral.org/assets/MGH/pdf/news/coronavirus/mass-generalCOVID-19-treatment-guidance.pdf (last accessed on June 24, 2020).

14- Saudi Arabia Ministry of Health Coronavirus disease 19 (COVID-19) guidelines, Saudi Arabia Ministry of Health, Riyadh (2020) Available at: https://www.moh.gov.sa/CCC/healthp/regulations/Documents/Coronavirus\%20D isease\%202019\%20Guidelines\%20v1.1..pdf (last accessed on June 24, 2020).

15- Health Protection Surveillance Centre Treatment guidelines for COVID-19 in Ireland HPSC, Dublin (2020). Available at:

https://www.hpsc.ie/az/respiratory/coronavirus/novelcoronavirus/guidance/guida nceforhealthcare (last accessed on June 24, 2020).

16- Higgins, J.P., Thomas J., Chandler, J., Cumpston, M., Li, T., Page, M.J., Welch, V.A. Cochrane handbook for systematic reviews of interventions: John Wiley \& Sons; 2019. 
medRxiv preprint doi: https://doi.org/10.1101/2020.06.16.20133298; this version posted June 19, 2020. The copyright holder for this preprint (which was not certified by peer review) is the author/funder, who has granted medRxiv a license to display the preprint in perpetuity.

It is made available under a CC-BY-NC-ND 4.0 International license .

17-Shamseer, L., Moher, D., Clarke, M., Ghersi D., Liberati, A., Petticrew, M., et al. Preferred reporting items for systematic review and meta-analysis protocols (PRISMA-P) 2015: elaboration and explanation BMJ 2015; 349: g7647. doi: https://doi.org/10.1136/bmj.g7647

18- Sarma P., Kaur, H., Kumar, H., et al. Virological and clinical cure in COVID-19 patients treated with hydroxychloroquine: A systematic review and meta-analysis [published online ahead of print, 2020 Apr 16]. J Med Virol. 2020;10.1002/jmv.25898. doi:10.1002/jmv.25898

19- Wang, Z., Nayfeh, T., Tetzlaff, J., O’Blenis, P., Murad, M.H. (2020) Error rates of human reviewers during abstract screening in systematic reviews. PLOS ONE 15(1): e0227742. https://doi.org/10.1371/journal.pone.0227742

20- Sterne, J.A.C., Savović, J., Page, M.J., et al. RoB 2: a revised tool for assessing risk of bias in randomised trials. BMJ. 2019;366: 14898. Published 2019 Aug 28. doi:10.1136/bmj. 14898

21- Sterne, J.A., Hernán, M.A., Reeves, B.C., et al. ROBINS-I: a tool for assessing risk of bias in non-randomised studies of interventions. BMJ. 2016;355: 14919. Published 2016 Oct 12. doi:10.1136/bmj. i4919

22- Wells, G.A., Tugwell, P., O’Connell, D., Welch, V., Peterson, J., Shea, B., Losos, M. The Newcastle-Ottawa Scale (NOS) for assessing the quality of nonrandomized studies in meta-analyses. 2015. Available at: https://www.scienceopen.com/document?vid=54b48470-4655-4081-b5d4e8ebe8d1792e

23- Li, Y., Xie, Z., Lin, W., Cai, W., *Wen C. Efficacy and safety of lopinavir/ritonavir or arbidol in adult patients with mild/moderate COVID-19: an exploratory randomized controlled trial..Available online 19 May 2020. https://doi.org/10.1016/j.medj.2020.04.001

24- Lan, X., Shao, C., Zeng, X., Wu, Z., Xu. Y. Lopinavir-ritonavir alone or combined with arbidol in the treatment of 73 hospitalized patients with COVID19: a pilot retrospective study. medRxiv 2020.04.25.20079079; doi: https://doi.org/10.1101/2020.04.25.2007907 $\underline{9}$

25- Yan, D.; Liu, X.; Zhu, Y.; Huang, L.; Dan, B.; Zhang, G.; Gao, Y. Factors associated with prolonged viral shedding and impact of Lopinavir/Ritonavir treatment in patients with SARS-CoV-2 infection. Eur Respir J. Jan 2020, 2000799; http;//doi: 10.1183/13993003.00799-2020 
medRxiv preprint doi: https://doi.org/10.1101/2020.06.16.20133298; this version posted June 19, 2020. The copyright holder for this preprint (which was not certified by peer review) is the author/funder, who has granted medRxiv a license to display the preprint in perpetuity. It is made available under a CC-BY-NC-ND 4.0 International license .

26-Zhu, Z., Lu, Z., Xu, T., et al. Arbidol monotherapy is superior to lopinavir/ritonavir in treating COVID-19 [published online ahead of print, 2020 Apr 10]. J Infect. 2020; S0163-4453(20)30188-2. doi: 10.1016/j.jinf.2020.03.060

27- Jun, C., Yun, L., Xiuhong, X., Ping, L. et al. Efficacies of lopinavir/ritonavir and abidol in the treatment of novel coronavirus pneumonia". 4 February 2020. Retrieved 24 February 2020. http://rs.yiigle.com/yufabiao/1182592.htm

28- Wen, C.Y., Xie, Z.W., Li, Y.P., et al. Zhonghua Nei Ke Za Zhi. Real-world Efficacy and Safety of Lopinavir/Ritonavir and Arbidol in Treating With COVID-19: An Observational Cohort Study. 2020;59(0): E012. doi:10.3760/cma.j.cn112138-20200227-00147

29- Cai, Q., Yang, M., Liu, D., et al. Experimental Treatment with Favipiravir for COVID-19: An Open-Label Control Study [published online ahead of print, 2020 Mar 18]. Engineering (Beijing). 2020;10.1016/j.eng.2020.03.007. doi:10.1016/j.eng.2020.03.007

30- Hung, I.F., Lung, K.C., Tso, E.Y., et al. Triple combination of interferon beta-1b, lopinavir-ritonavir, and ribavirin in the treatment of patients admitted to hospital with COVID-19: an open-label, randomised, phase 2 trial. Lancet. 2020;395(10238):1695-1704. doi:10.1016/S0140-6736(20)31042-4

31- Ye, X.T., Luo, Y.L., Xia, S.C., et al. Clinical efficacy of lopinavir/ritonavir in the treatment of Coronavirus disease 2019. Eur Rev Med Pharmacol Sci. 2020;24(6): pp. 3390-3396. doi:10.26355/eurrev_202003_20706

32- Yuan, J., Zou, R., Zeng, L., et al. The correlation between viral clearance and biochemical outcomes of 94 COVID-19 infected discharged patients. Inflamm Res. 2020;69(6): pp. 599-606. doi:10.1007/s00011-020-01342-0

33- Deng, L., Li, C., Zeng, Q., Liu, X., Li, X., Zhang, H. Arbidol combined with $\mathrm{LPV} / \mathrm{r}$ versus LPV/r alone against corona virus disease 2019: a retrospective cohort study. J Infect. 2020 doi: 10.1016/j.jinf.2020.03.002. In press

34- Lian, N., Xie, H., Lin, S., Huang, J., Zhao, J., Lin, Q. Umifenovir treatment is not associated with improved outcomes in patients with coronavirus disease 2019: a retrospective study [published online ahead of print, 2020 Apr 25]. Clin Microbiol Infect. 2020;S1198-743X(20)30234-2. doi:10.1016/j.cmi.2020.04.026 
medRxiv preprint doi: https://doi.org/10.1101/2020.06.16.20133298; this version posted June 19, 2020. The copyright holder for this preprint (which was not certified by peer review) is the author/funder, who has granted medRxiv a license to display the preprint in perpetuity.

It is made available under a CC-BY-NC-ND 4.0 International license.

35- Haviernik, J., Stefanik, M., Fojtikova, M., Kali, S., Tordo, N., Rudolf, I., Hubalek, Z., Eyer, L., Ruzek, D.: Arbidol (Umifenovir): A Broad-Spectrum Antiviral Drug That Inhibits Medically Important Arthropod-Borne Flaviviruses. Viruses. 2018 Apr 10;10(4). pii: v10040184. doi: 10.3390/v10040184.

36- Tobaiqy, M., Helmi, N., Majrashi, M. et al. COVID-19 Therapeutics Outcome: Systematic Review and Data Analysis, 05 June 2020, PREPRINT (Version 1) available at Research Square [+https://doi.org/10.21203/rs.3.rs-33391/v1+] 